Research Article

\title{
Comparison Evaluations of VRF and RTU Systems Performance on Flexible Research Platform
}

\author{
Je-hyeon Lee, ${ }^{1}$ Piljae Im, ${ }^{2}$ Jeffrey D. Munk $\mathbb{D}^{2}{ }^{2}$ Mini Malhotra, ${ }^{2}$ Min-seok Kim, ${ }^{3}$ \\ and Young-hak Song $\mathbb{1}^{4}$ \\ ${ }^{1}$ Department of Digital Appliances ReD Team, Samsung Electronics, Suwon 17804, Republic of Korea \\ ${ }^{2}$ Building Technologies Research and Integration Center (BTRIC), Oak Ridge National Laboratory, One Bethel Valley Road, \\ Oak Ridge, TN 37831, USA \\ ${ }^{3}$ Department of Architectural Engineering, Graduate School of Gyeongsang National University, Jinju 52828, Republic of Korea \\ ${ }^{4}$ Department of Architectural Engineering, ERI, Gyeongsang National University, Jinju 52828, Republic of Korea
}

Correspondence should be addressed to Young-hak Song; songyh@gnu.ac.kr

Received 19 November 2017; Accepted 12 February 2018; Published 5 April 2018

Academic Editor: Alison Kwok

Copyright ( 2018 Je-hyeon Lee et al. This is an open access article distributed under the Creative Commons Attribution License, which permits unrestricted use, distribution, and reproduction in any medium, provided the original work is properly cited.

\begin{abstract}
The energy performance of a variable refrigerant flow (VRF) system was evaluated using an occupancy-emulated research building in the southeastern region of the United States. Full- and part-load performance of the VRF system in heating and cooling seasons was compared with a conventional rooftop unit (RTU) variable-air-volume system with electric resistance heating. During both the heating and cooling seasons, full- and part-load conditions (i.e., $100 \%, 75 \%$, and $50 \%$ thermal loads) were maintained alternately for 2 to 3 days each, and the energy use, thermal conditions, and coefficient of performance (COP) for the RTU and VRF system were measured. During the cooling season, the VRF system had an average COP of 4.2, 3.9, and 3.7 compared with $3.1,3.0$, and 2.5 for the RTU system under $100 \%, 75 \%$, and $50 \%$ load conditions and resulted in estimated energy savings of $30 \%$, $37 \%$, and $47 \%$, respectively. During the heating season, the VRF system had an average COP ranging from 1.2 to 2.0 , substantially higher than the COPs of the RTU system, and resulted in estimated energy savings of $51 \%$, $47 \%$, and $27 \%$ under the three load conditions, respectively.
\end{abstract}

\section{Introduction}

VRF (Variable Refrigerant Flow) system has been used in many countries in Europe and Asia for more than 30 years since it was invented in Japan in 1982 [1]. There are known benefits of VRF systems such as easier modular installation, space efficiency, responsiveness to fluctuating loads, and higher efficiency, but several studies [2-6] show that there are concerns regarding the application of VRF systems in the USA, including (1) lack of awareness of energy efficiency advantages, (2) higher first cost, and (3) lack of understanding about the suitability of the VRF system for the building operation profile in the USA. The performance of VRF systems in the USA has been measured mainly in chambers; however, performance measurement of VRF system in real buildings is challenging due to the complexity of the system and occupancy-related uncertainties. The present paper compared the performance of existing HVAC (RTU, Rooftop Unit) and VRF system in Oak Ridge National Laboratory (ORNL)'s two-story Flexible Research Platform (FRP) during the heating and cooling period. In order to evaluate the performance of the two systems, three load conditions (i.e., $100 \%, 75 \%$, and 50\%) were applied to the test facility, and each system was operated alternately for 2 to 3 days, respectively $[7,8]$. The three load conditions were applied to the entire building or selected zones, and the energy use, thermal conditions, and the COP were measured.

\section{Methodology}

2.1. Test Facility. The test facility is a two-story, $297.3 \mathrm{~m}^{2}$ multizone unoccupied building that represents a typical 


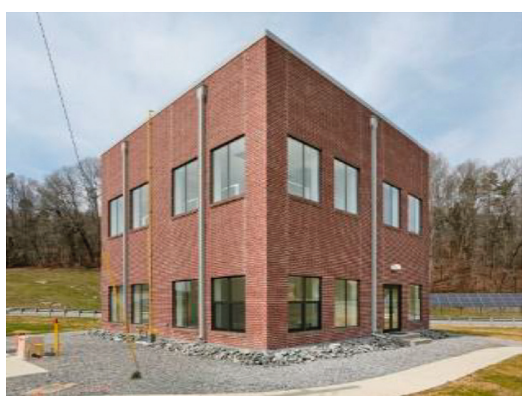

(a)

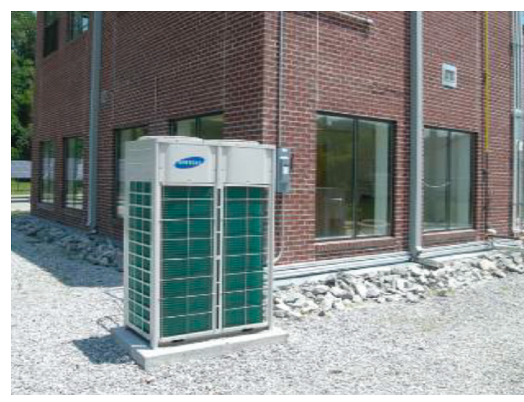

(b)

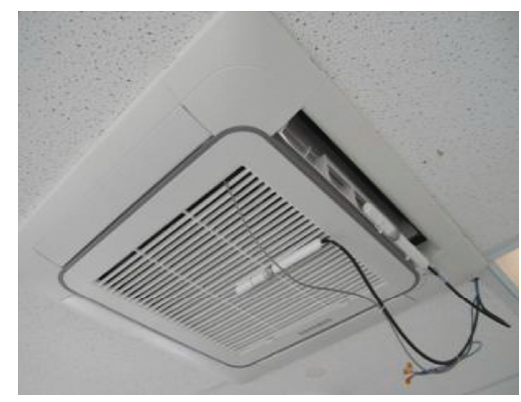

(c)

Figure 1: Test facility (a), VRF system outdoor unit (b), and indoor unit (c).

TABLE 1: Building and HVAC system specification.

\begin{tabular}{|c|c|}
\hline Location & Oak Ridge, Tennessee, USA \\
\hline Building size & Two-story, $12.2 \mathrm{~m} \times 12.2 \mathrm{~m}, 4.3 \mathrm{~m}$ floor-to-floor height \\
\hline Exterior walls & Concrete masonry units with face brick, $\mathrm{R}_{\mathrm{US}^{-}}-11\left(\mathrm{R}_{\mathrm{SI}^{-}}-1.9\right)$ fiberglass insulation \\
\hline Floor & Slab-on-grade \\
\hline Roof & Metal deck with $\mathrm{R}_{\mathrm{US}}-18\left(\mathrm{R}_{\mathrm{SI}^{-}}-3.17\right)$ polyisocyanurate insulation \\
\hline Windows & Double-pane clear glazing, $28 \%$ window-to-wall ratio \\
\hline Baseloads & $9.18 \mathrm{~W} / \mathrm{m}^{2}$ lighting power density, $14.04 \mathrm{~W} / \mathrm{m}^{2}$ equipment power density \\
\hline Baseline HVAC system & $\begin{array}{c}44 \mathrm{~kW} \text {, } 9.7 \text { EER rooftop unit; } 81 \% \text { AFUE natural gas furnace; VAV terminal units and } \\
\text { electric reheat }\end{array}$ \\
\hline VRF system & $42 \mathrm{~kW}$ VRF system with a DOAS \\
\hline
\end{tabular}

low-rise, small office building common in the US existing building stock (Figure 1(a)). The occupancy in the building can be simulated by process control of lighting and other internal loads. On this building, retrofits and alternative building components and systems can be implemented and their performance monitored. In addition, a dedicated weather station is installed on the roof that provides actual weather data for use in performance analysis and energy modeling. The building is equipped with a conventional $44 \mathrm{~kW}$ RTUVAV (Rooftop Unit with a Variable Air Volume) reheat system. For this study, a $42 \mathrm{~kW}$ VRF with a DOAS (Dedicated Outdoor Air System) was installed (Figures 1(a)-1(c)); the existing RTU system served as the baseline system. Table 1 summarizes the baseline building and system specification.

2.2. HVAC Systems. Figure 2 shows a schematic of the two systems. The RTU provides direct expansion cooling, heating with a natural gas furnace, and electric resistance reheat at VAV terminal units. The return air is drawn from each room through an above-ceiling plenum on each floor. Fresh air is introduced through the fan to provide adequate ventilation in accordance with ASHRAE Standard [9, 10]; therefore, fresh air uses dotted line in Figure 2. An exhaust fan is located on each floor and operates continuously. The RTU is programmed to maintain a constant discharge air temperature at $14^{\circ} \mathrm{C}$ during the cooling season. During the heating season, the RTU discharge air temperature was adjusted based on an OA reset schedule (Figure 3 ). The natural gas furnace would engage if the return air temperature to the RTU dropped below the discharge air set point temperature. In the cooling mode (i.e., discharge temperature set at $14^{\circ} \mathrm{C}$ ), the electric resistance reheat in the VAV terminal boxes in individual zones activates to provide necessary heat to maintain the desired zone temperature. The VRF system has a $42 \mathrm{~kW}$ outdoor unit, one DOAS unit, and ten indoor units with capacities ranging from 1.8 to $5.3 \mathrm{~kW}$. The ten indoor units and the DOAS are connected to the same VRF outdoor condensing unit, and the DOAS provides conditioned OA to ten zones at $0.189 \mathrm{~m}^{3} / \mathrm{s}$. Note that the VRF system in this test is a heat pump-type system that provides only cooling or heating at any single time and cannot provide simultaneous heating and cooling for different thermal zones.

2.3. Building Operation. The VRF and the baseline RTU system performance was evaluated by comparing their hourly and daily energy use and the indoor thermal condition (i.e., temperature). Figure 4 illustrates the schematic of operation to emulate (a) $50 \%$ load, (b) $75 \%$ load, and (c) $100 \%$ load. Each system was operated alternately for 8 consecutive days with 3 days each for $50 \%$ and $75 \%$ and 2 days for $100 \%$ loads. There was no discrete weekday and weekend schedule; the same occupancy schedule was used for all days.

The cooling season analysis was based on the measured data from July 11 through September 12, 2015. During this period, the RTU system was operated for 9 days at $50 \%$ load, 13 days at $75 \%$ load, and 8 days at $100 \%$ load. The VRF system was operated for 9 days at 50\% load, 9 days at $75 \%$ load, and 6 days at $100 \%$ load. The heating season analysis is based on measured data from December 30, 2015, through March 6, 2016. During this period, the RTU system was 


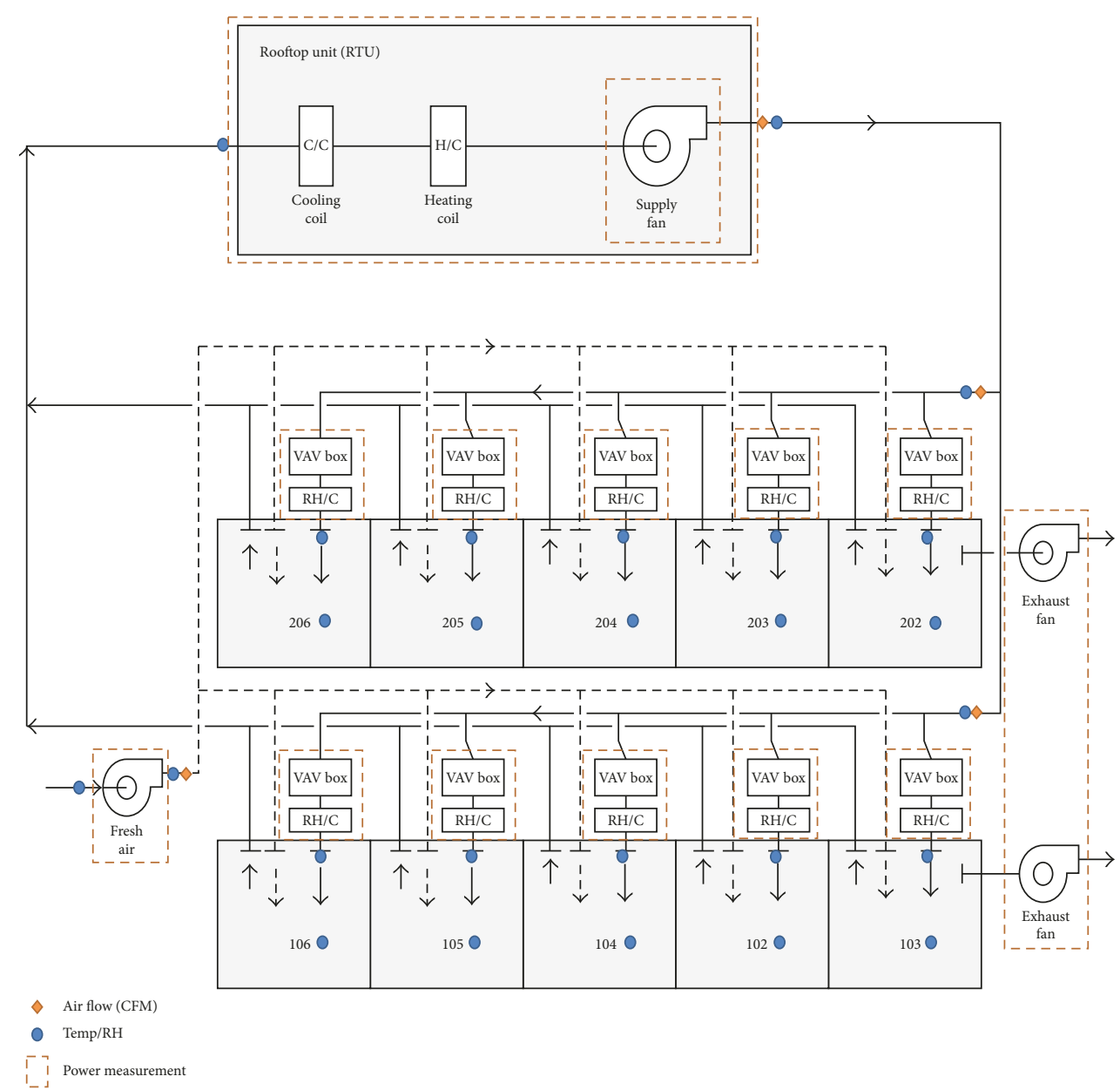

(a)

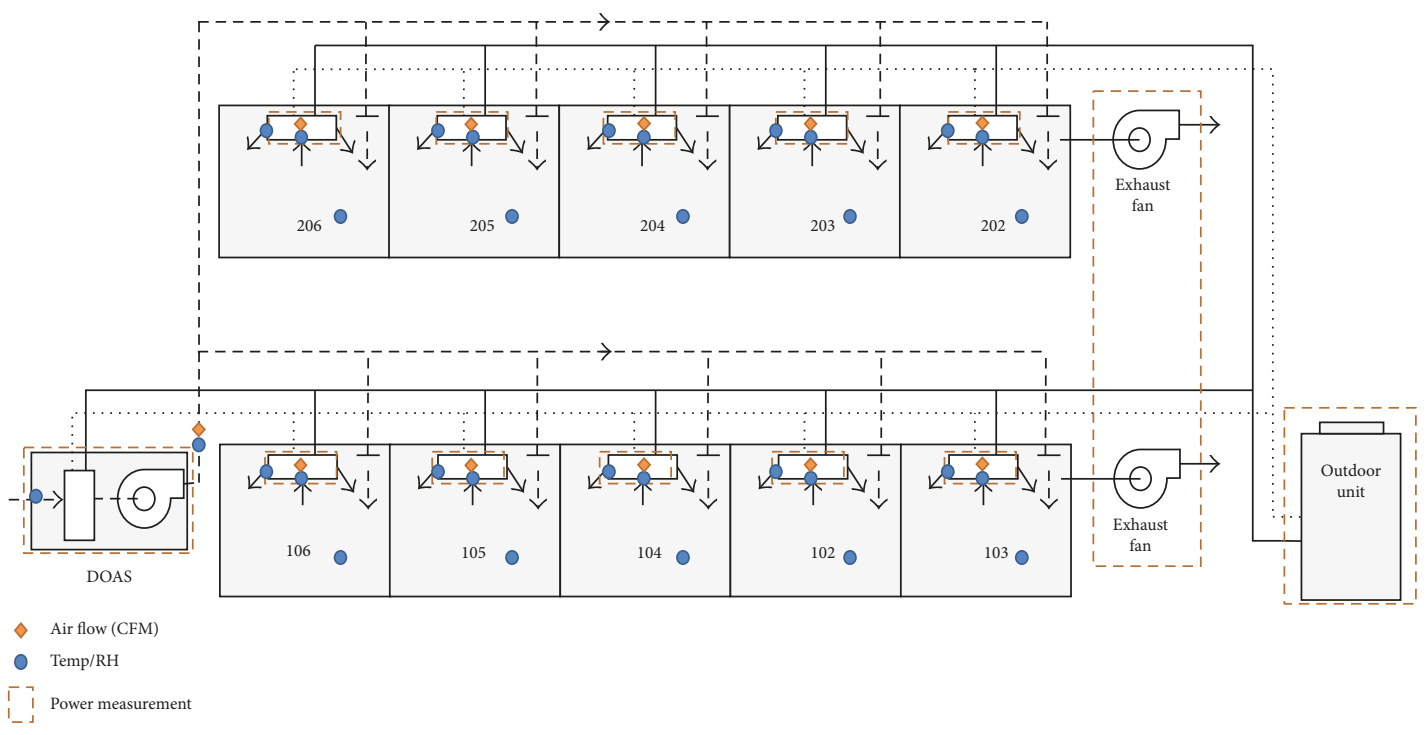

(b)

FIgURE 2: System schematic and monitoring points for RTU system (a) and VRF system (b).

operated for 9 days at 50\% load, 9 days at $75 \%$ load, and 13 days at $100 \%$ load. The VRF system was operated for 9 days at 50\% load, 12 days at $75 \%$ load, and 11 days at $100 \%$ load. Based on the schedule, occupancy emulation was also controlled so that only conditioned rooms had emulated occupancy. 


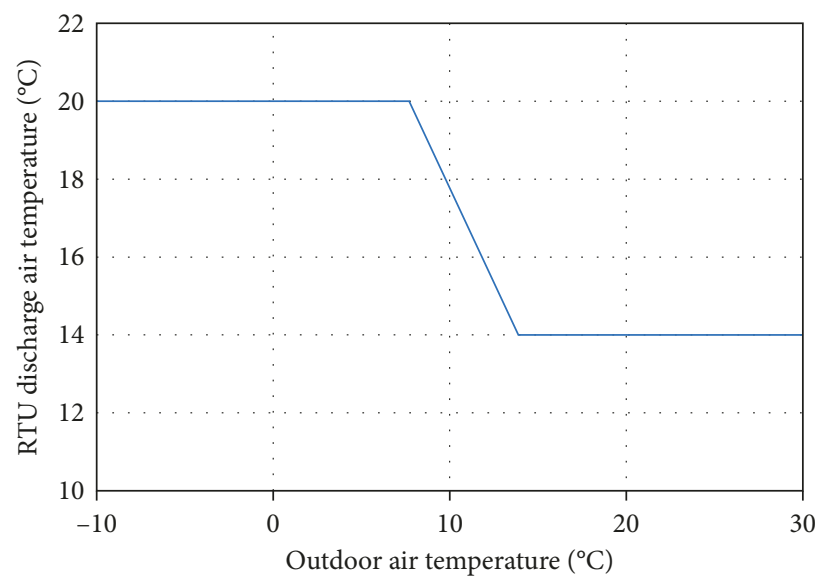

FIgURE 3: OA reset schedule for RTU discharge temperature.

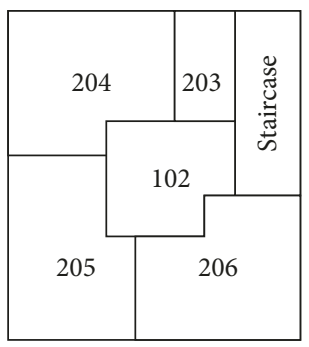

Second floor

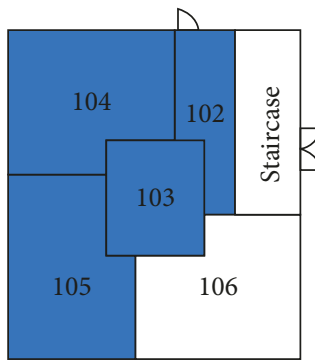

First floor

Conditioned zone

Unconditioned zone

(a)

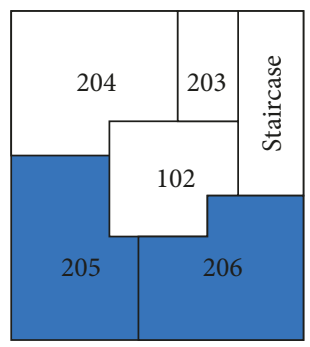

Second floor

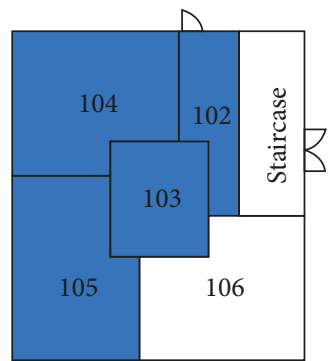

First floor

Conditioned zone

Unconditioned zone

(b)

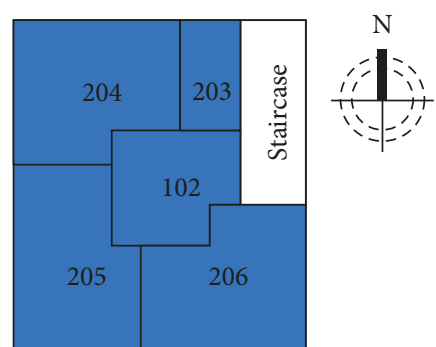

Second floor

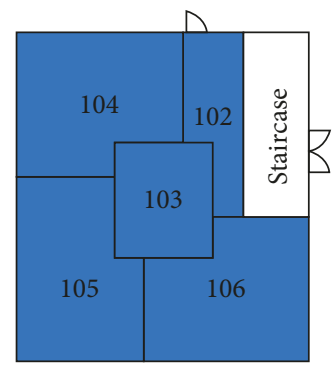

First floor

Conditioned zone

Unconditioned zone

(c)

Figure 4: Schematic of operation to emulate (a) $50 \%$ load, (b) $75 \%$ load, and (c) $100 \%$ load.

2.4. Evaluation Metrics. The performance of the RTU and VRF systems was compared in terms of (1) energy use, (2) ability to maintain room temperature, and (3) system efficiency. The energy use and thermal performance comparison were performed using measured hourly data for occupied hours only (i.e., 8 a.m. to 6 p.m.), excluding the startup hours. The coefficient of performance (COP) analysis was performed using both hourly and 1-minute data. Figure 2 shows the air-side monitoring points, which include the room temperature and relative humidity, supply, return, and mixed-air temperature and relative humidity. The airflow rate was measured at the RTU supply, upstairs and downstairs of the supply duct, and at the fresh air supply for the RTU system. For the VRF system, one-time airflow measurements were conducted for each indoor unit, and the DOAS supply side for the VRF system was measured continuously. Power measurements were obtained separately for the RTU unit, the supply fan, and the DOAS fan for the baseline RTU system. Power consumption for the VRF outdoor unit, each VRF indoor unit, and the DOAS was measured as well. The measured supply, return temperature and relative humidity, and airflow were used to calculate the delivered heating and cooling loads to the building and the system COP as well. 

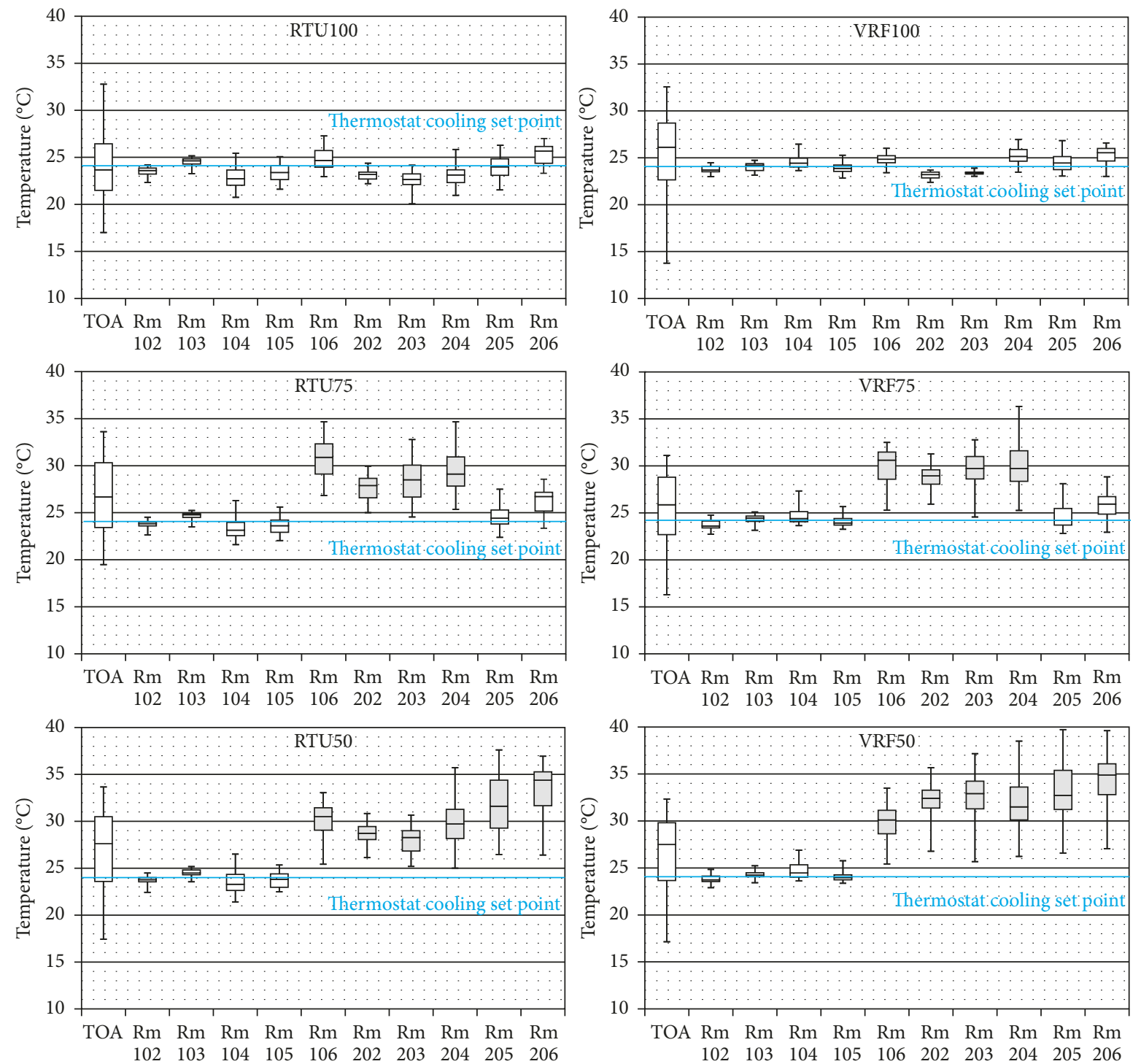

FIgURE 5: Room temperatures for RTU and VRF system.

\section{Cooling Analysis}

3.1. Cooling Hourly Thermal Condition Analysis. Figure 5 shows the measured hourly room temperature statistics (minimum, first quartile, median, third quartile, and maximum) for occupied hours excluding the startup hours (8 a.m. to 6 p.m.) in all rooms during RTU and VRF system operation at the three load conditions. Outdoor air temperature statistics are also plotted. The thermostat cooling set point is marked as a blue line across the plot. Temperature statistics in unconditioned rooms are shaded in gray.

The data analysis shows that both the RTU and the VRF systems maintained room temperature well, especially in the first-floor rooms. In general, the VRF system maintained room temperature in a slightly tighter range compared with the RTU system. Some rooms on the second floor were slightly undercooled for both systems during $100 \%$ operation. For $100 \%$ VRF system operation, rooms 204, 205, and 206 showed slight undercooling, which implies that the VRF indoor units might be slightly undersized. For 100\% RTU operation, only room 206 showed slight undercooling, and rooms 202, 203, and 204 were overcooled. The RTU part-load schedules were lower than the ones during the corresponding VRF part-load schedules. This likely was the case because the room air was better isolated during VRF system operation. During part-load operation for the RTU system, the VAV boxes in the unconditioned rooms were forced to close to prevent these rooms from being directly conditioned. However, there could have been some leakage through the damper in the VAV box that allowed a small amount of conditioned air to be provided to the unconditioned zones. In addition, the return air grilles connecting to the return air plenum of the RTU were not closed, resulting in depressurization of the unconditioned rooms while the RTU supply fan was running. This depressurization may have caused conditioned air from other rooms to be pulled into the unconditioned rooms via door undercuts or other leakage paths. The addition of this conditioned air by either VAV damper leakage or pressure-driven air movement from 


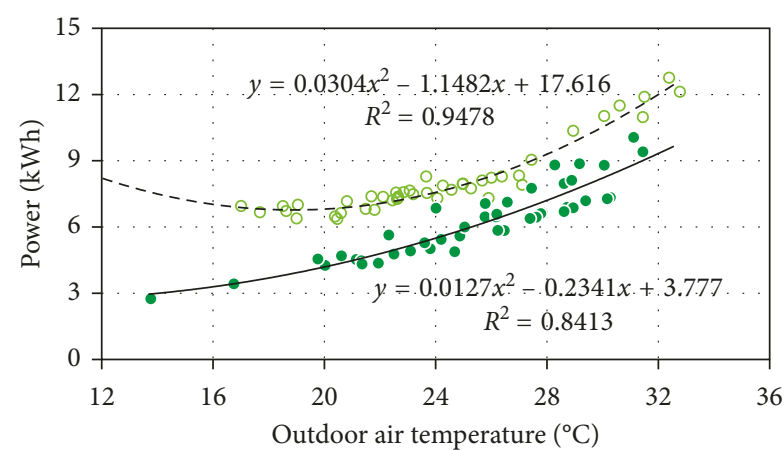

○ RTU100

- VRF100

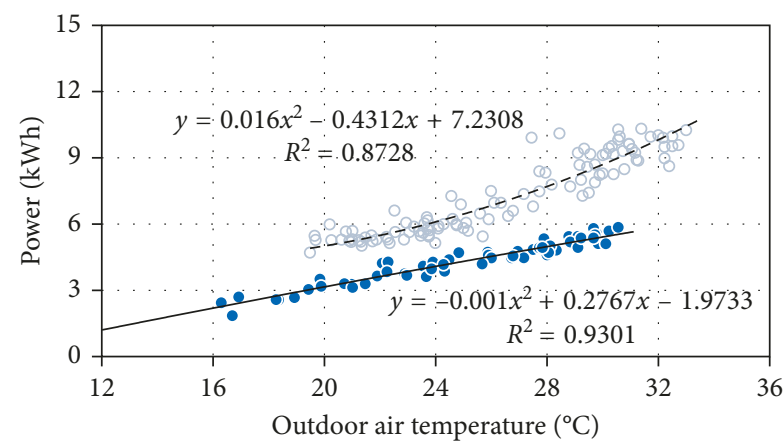

○TU75

- VRF75

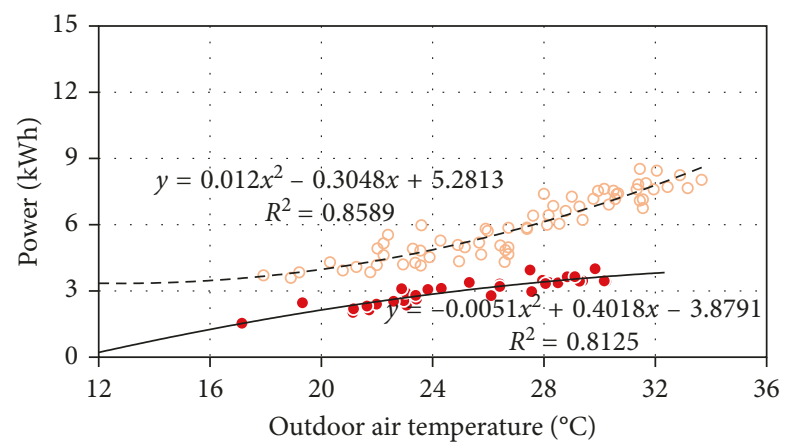

RTU50

- VRF50

FIGURE 6: Comparison of hourly power consumption by VRF and RTU systems at each load condition.

conditioned rooms could have contributed to lower room temperatures in the unconditioned rooms during RTU operation.

3.2. Cooling Season Power Consumption Analysis. A comparison of data across the RTU and VRF systems by load in Figure 6 shows that energy use was higher for the RTU system than for the VRF system at full- and part-load conditions. To predict the hourly energy use for each operation in the entire cooling season, best-fit regression models for RTU and VRF hourly energy use were also developed, as shown in Figure 6, which presents the regression models for the RTU and VRF hourly energy use based on the average hourly outdoor air temperature.

Figures 7 and 8 show power consumption comparison during the occupied hours when the RTU and VRF systems were operated under varying loads. The VRF system responded more efficiently to the reduced loads (i.e., use less energy for lower loads), as seen from the lower scatter in the data points for the three loads. The energy use by the RTU system was more scattered during part-load conditions, resulting in more overlapping points for the 50\% and 75\% load schedules. These results indicate that the VRF system does a better job of isolating zone air during operation, whereas return air from conditioned zones and warm air from unconditioned zones mixes in the plenum during RTU system operation.

3.3. Cooling Season COP Analysis. Figure 9 shows the COP of the VRF and RTU systems with respect to outdoor air temperature. As discussed earlier, the operating efficiency of the VRF system was more sensitive to outdoor temperature driven loads (i.e., COP is lower at cooler temperatures). At lower outdoor air temperatures, the impact of zone controldriven variability in loads was observed. At higher temperatures, that impact diminished. The efficiency of the RTU system showed a similar trend (lower COP at 50\% load, even lower at cooler temperatures), but the impact was less pronounced. Over the data monitoring period, the average cooling COP was 4.2, 3.9, and 3.7 for the VRF system and 3.1, 3.0, and 2.5 for the RTU system under $100 \%, 75 \%$, and $50 \%$ load conditions, respectively. These results show $35 \%, 30 \%$, and $48 \%$ improvement in COP for $100 \%, 75 \%$, and $50 \%$ load conditions, respectively.

3.4. Quasi-Steady-State COP Analysis. Analyzing highresolution data (i.e., 1 minute data) allows further insight into the equipment operation by enabling the filtering of near-steady-state data and the separation of the data by operating stage or capacity. The following sections will analyze the equipment performance from a quasi-steady-state perspective and then determine the impact of cycling losses on each system.

Using the quasi-steady-state data set, the COP of the RTU is plotted against outdoor temperature in Figure 10. The outdoor air temperature was binned in $2.8^{\circ} \mathrm{C}$ increments; for example, the $25^{\circ} \mathrm{C}$ bin includes temperatures greater than or equal to $23.9^{\circ} \mathrm{C}$ and less than $26.7^{\circ} \mathrm{C}$. The data were also divided by compressor staging, with the low stage representing single-compressor operation and the high stage representing dual-compressor operation. As expected, the efficiency of the system decreased with increasing ambient temperature. And the trend of higher efficiency during low stage operation is not consistently seen in the different operating schedules. This can be explained by looking at both the outdoor and indoor airflow. The outdoor airflow, as indicated by fan power, did not change between high and low stage. It is likely that the outdoor fan is running at a higher than-optimal speed in low stage resulting in excess fan power and reduced efficiency. The indoor blower on the RTU varies its speed in order to 


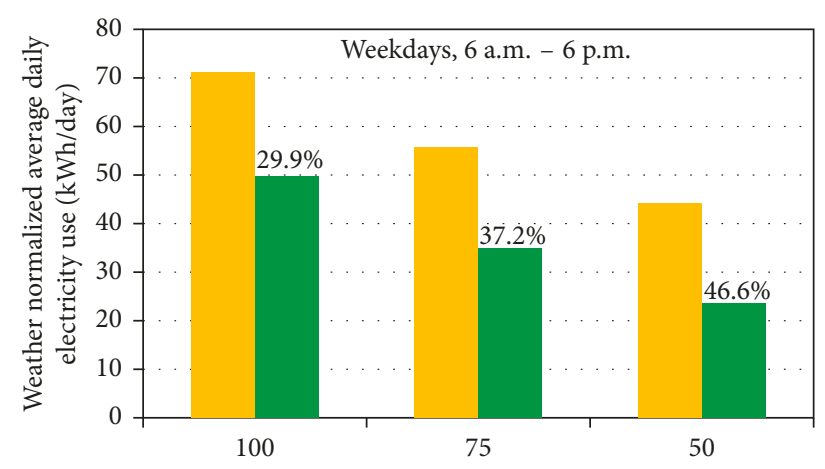

$(\%)$

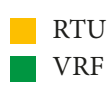

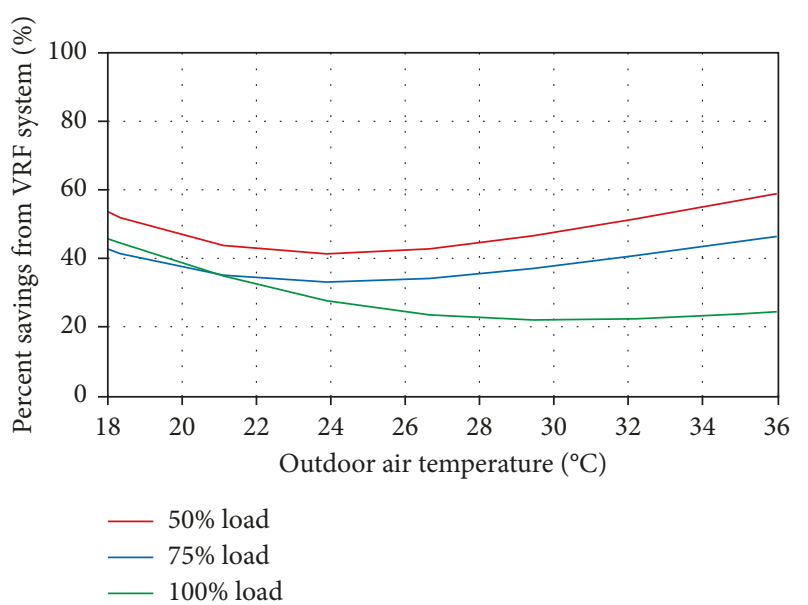

(b)

(a)

FIgURE 7: Energy savings from VRF system at different loads.

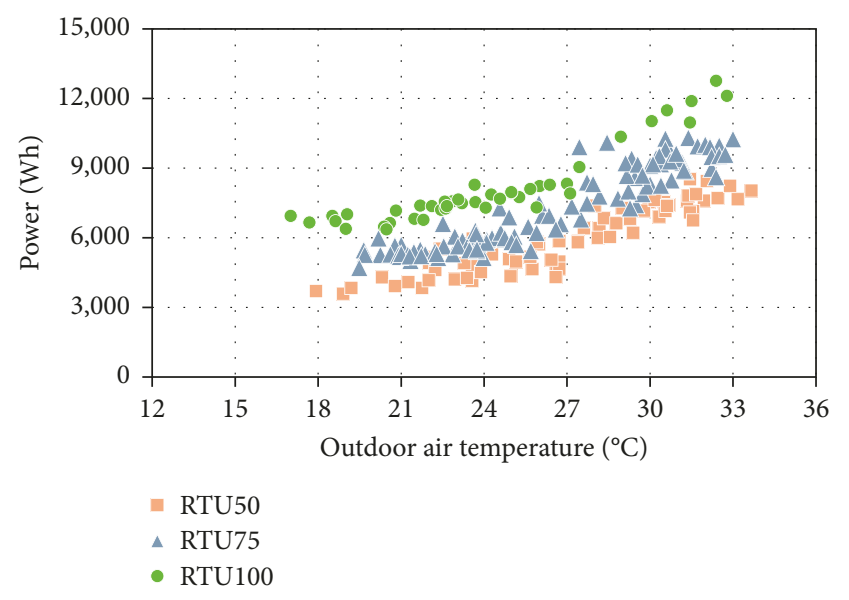

(a)

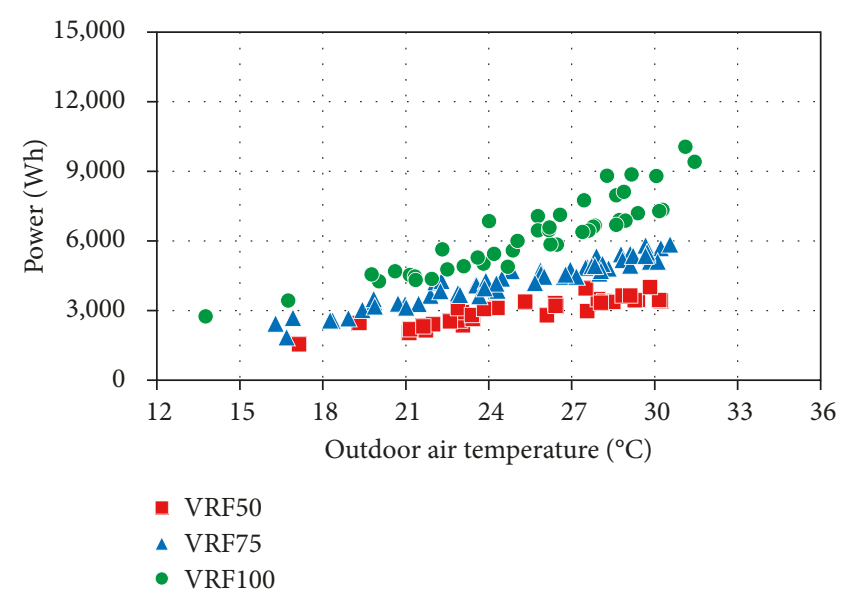

(b)

FIgURE 8: Comparison of hourly power consumption during occupied hours at varying loads.

maintain a constant static pressure in the duct system, so the number VAV boxes that are open determines the airflow. This results in the RTU100 schedule having the highest indoor airflow and the RTU50 schedule having the lowest. The indoor airflow is independent of the compressor staging though, resulting in a wide range in the ratio of indoor airflow to cooling capacity from 20 to $50 \mathrm{~m}^{3} / \mathrm{min}$ per $\mathrm{kW}$ of cooling. Generally, the optimal indoor fan speed for efficiency falls somewhere in the middle of this range, with higher airflows resulting in excessive fan power and lower airflows resulting in lower suction saturation temperatures and therefore higher compressor power. The RTU75 low stage operation and RTU100 high stage operation fell closest to the $35 \mathrm{~m}^{3} / \mathrm{min}$ per $\mathrm{kW}$ of cooling airflow and exhibit the highest efficiencies of their respective stages. The best efficiency is achieved at an optimal balance between capacity, airflow, and fan power.

The VRF data were filtered in the same fashion as the RTU data, using a 10-minute minimum runtime as the limit for quasi-steady-state data. This schedule included a 10-minute minimum runtime between the time when individual indoor units turn on or off. An indoor unit was considered to be actively cooling if the fan was operating and the temperature differential between the return and supply was greater than $5.5^{\circ} \mathrm{C}$. The VRF100 schedule the highest efficiency over most of the temperature range, with the other schedules having similar efficiency at high outdoor air temperatures. Figure 11 shows a plot of the system COP as a function of outdoor air temperature and of the ratio of the rated capacity of the actively cooling indoor units to the total rated indoor unit capacity. The data from the different schedules are shown with different styles of markers, and the color of the marker and the label indicate the average COP for the data. Generally, the more indoor units that are actively cooling, the higher the system efficiency.

To examine the impact of compressor speed on efficiency, the data were filtered to include only times when the rated cooling capacity of the active indoor units was $80 \%$ of the total rated indoor capacity. This filtering limited the data to times when nearly all of the indoor units were providing cooling. 


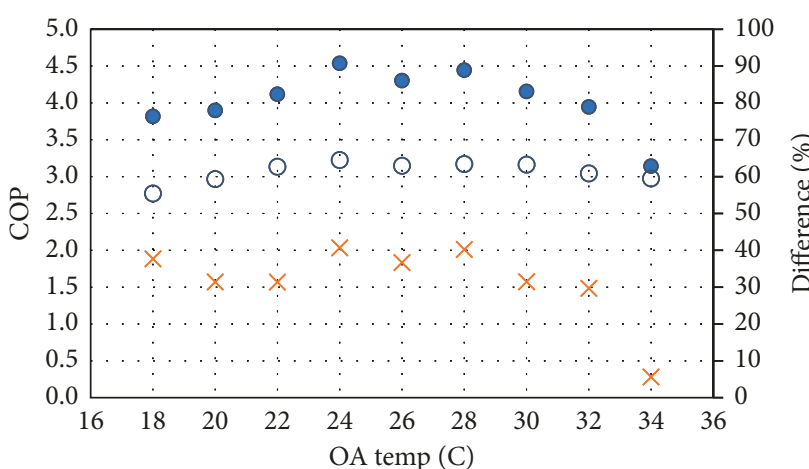

VRF100

RTU100

$\times \operatorname{Diff}(\%)$

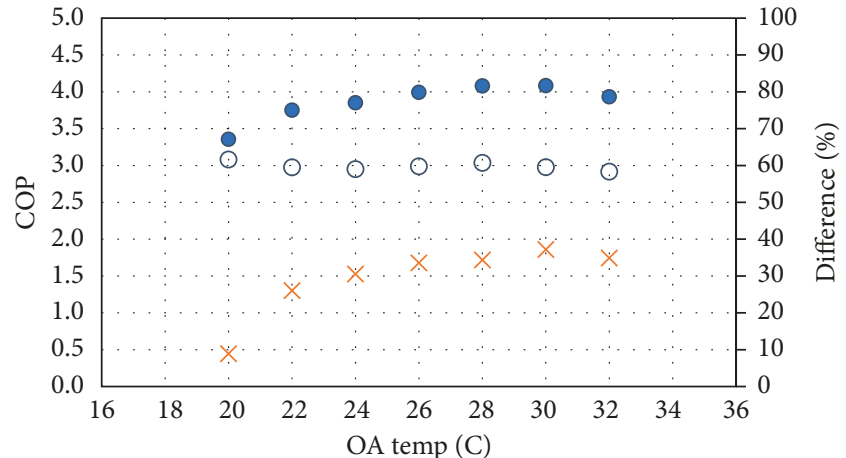

VRF75

RTU75

$\times \operatorname{Diff}(\%)$

(a)

(b)

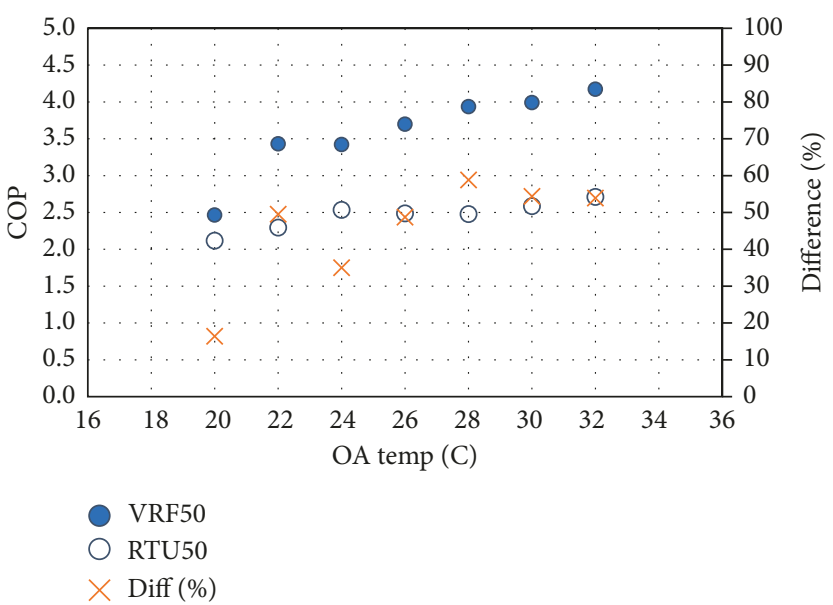

(c)

Figure 9: COP comparison between RTU and VRF systems.

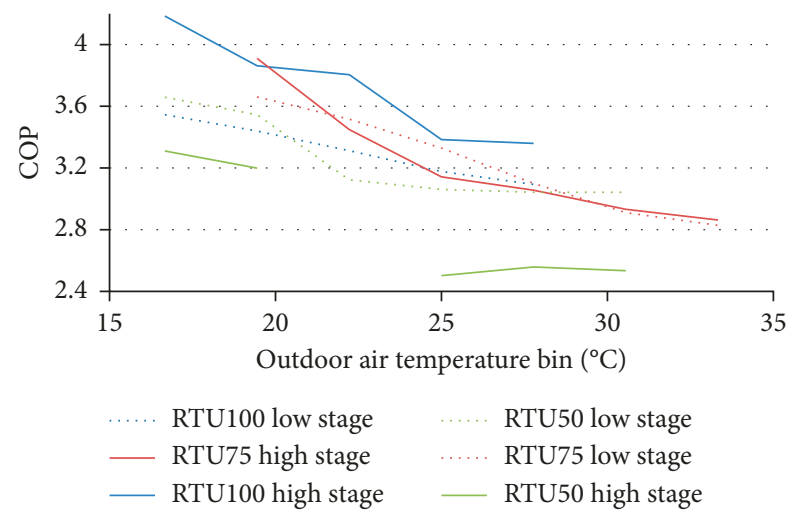

Figure 10: Comparison of RTU efficiency during different schedules.

The actual cooling capacity was then divided by the total rated cooling capacity, and these data were placed into 0.1 increment bins. The efficiency of this binned data was plotted against the binned outdoor air temperature data, as seen in Figure 12. These data show that, in general, the VRF system was more efficient when operating at lower compressor speeds, indicated by lower capacity in this case. The quasisteady-state data analysis indicates that the VRF system operated most efficiently when all indoor units were actively cooling and the compressor was operating at reduced speed. When indoor units were shut off, the cumulative size of the indoor heat exchanger was effectively reduced, thereby reducing the efficiency. However, as shown in the hourly analysis, this efficiency penalty was less than the energy saved by the reduced cooling load due to unoccupied zones not being conditioned.

\section{Heating Analysis}

4.1. Heating Hourly Thermal Condition Analysis. Figure 13 shows the measured hourly room temperature for the occupied hours (8 a.m. to 6 p.m.; i.e., excluding the startup hours) in all rooms during RTU and VRF system operation at the three capacities during heating season. Outdoor air temperature (OAT) statistics are also plotted. The thermostat heating set point is marked as a red line across the plot. Temperature statistics in unconditioned rooms are shaded in gray. During the heating season, in general, the 


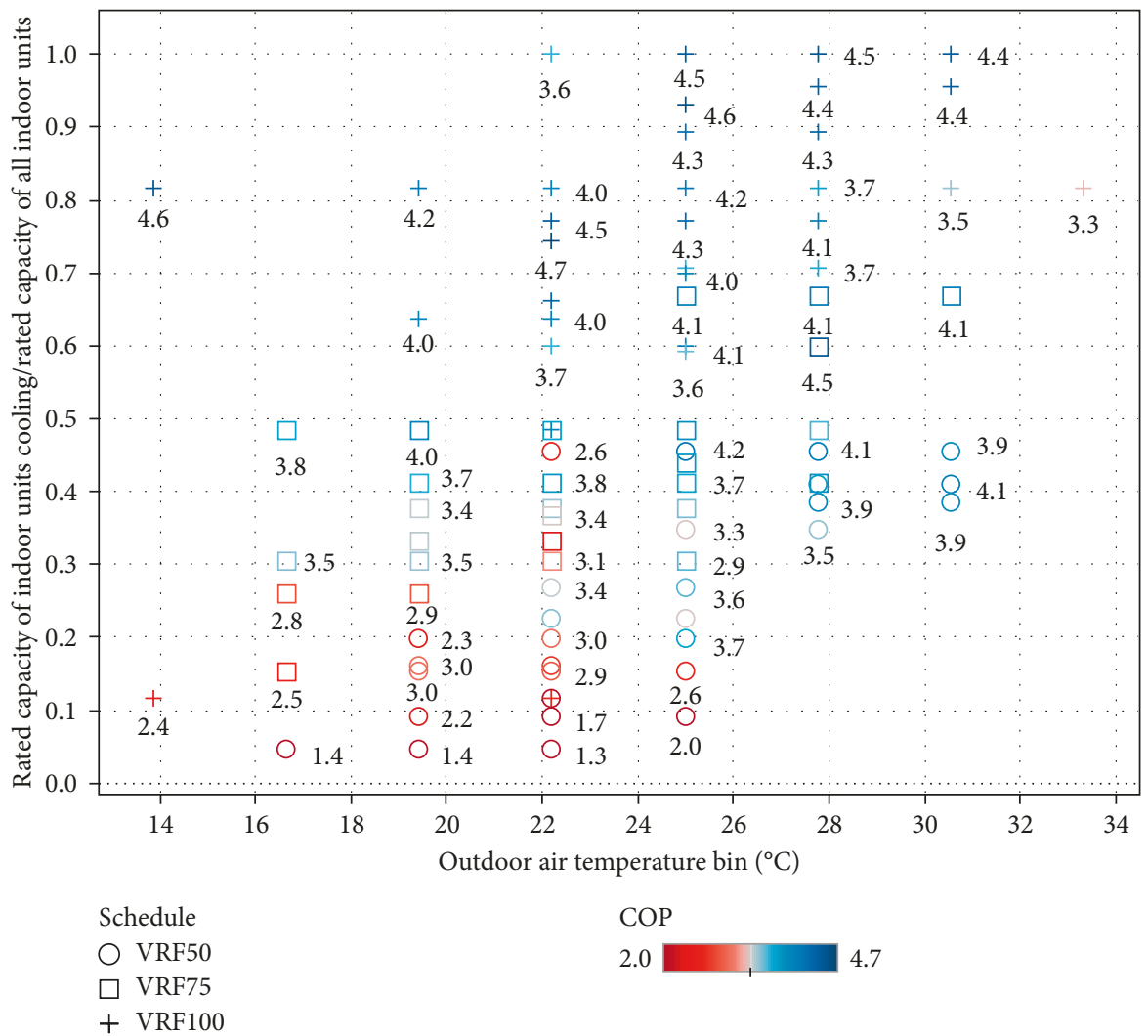

FIGURE 11: Impact of the rated capacity of active indoor units on the efficiency of the VRF system in summer.

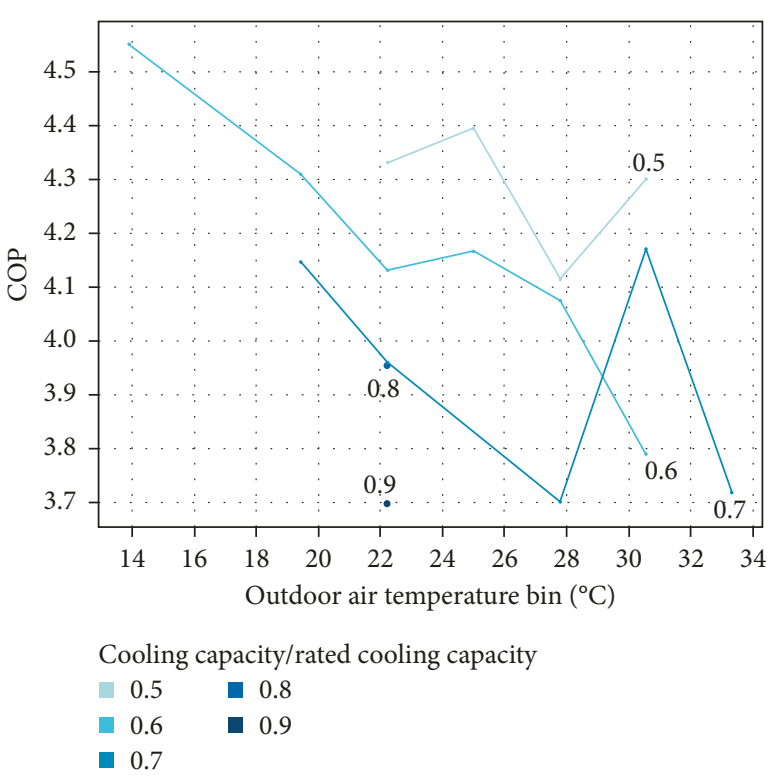

Figure 12: Efficiency of VRF system due to the rated cooling capacity in summer.

RTU system provided better thermal control for most of the rooms; rooms 205 and 206, which were overheated, were the exception. Those two rooms face south, east, and west, and it was observed that they were overheated mainly as a result of high solar heat gain through the windows during early morning and late afternoon.
For all three operation modes, the VRF system overheated rooms. There are a few reasons for this. As the installed VRF system cannot provide simultaneous cooling and heating, rooms that required cooling during the heating season were overheated. In most cases, the room temperatures stayed below $27^{\circ} \mathrm{C}$. The VRF system also experienced the same solar gains as the RTU, leading to overheating of rooms with south-, east-, and west-facing glazing. This type of small office building with a high window area should have a heat recovery-type VRF system so that the system can meet the building's simultaneous cooling and heating demands during the heating and shoulder seasons.

4.2. Heating Season Power Consumption Analysis. Figure 14 shows a comparison of power consumption during the occupied hours when the RTU and VRF systems were operated under different loads. The electricity used by the RTU operation is a sum of the electricity used by the RTU (compressor + condenser fan) and by the VAV electric reheating equipment. In addition, natural gas was used by the RTU gas furnace.

The VRF system shows a relatively strong correlation between energy use and the OAT, whereas the RTU total energy does not show a strong trend with the OAT. Hence, developing a weather-normalized model for RTU energy use requires considering many more issues than does the RTU model for cooling season.

The RTU natural gas heating and direct exchange cooling operate to maintain the desired supply air temperature 

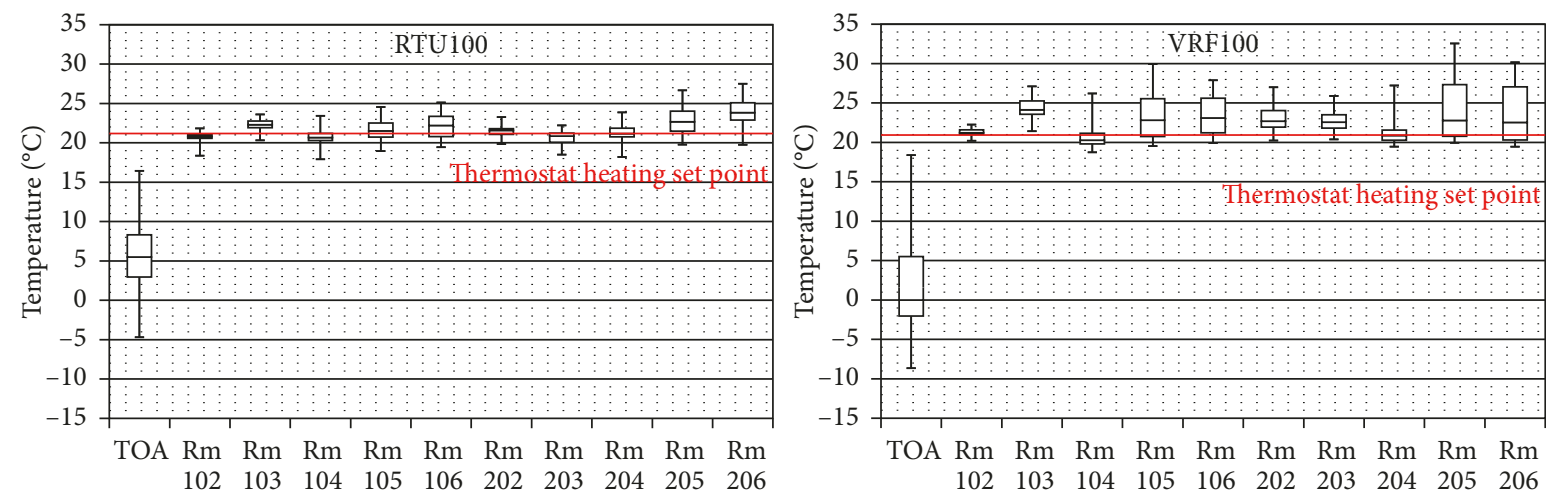

TOA Rm $\mathrm{Rm} \quad \mathrm{Rm} \quad \mathrm{Rm} \quad \mathrm{Rm} \quad \mathrm{Rm} \quad \mathrm{Rm} \quad \mathrm{Rm} \quad \mathrm{Rm} \quad \mathrm{Rm}$ $\begin{array}{llllllllll}102 & 103 & 104 & 105 & 106 & 202 & 203 & 204 & 205 & 206\end{array}$
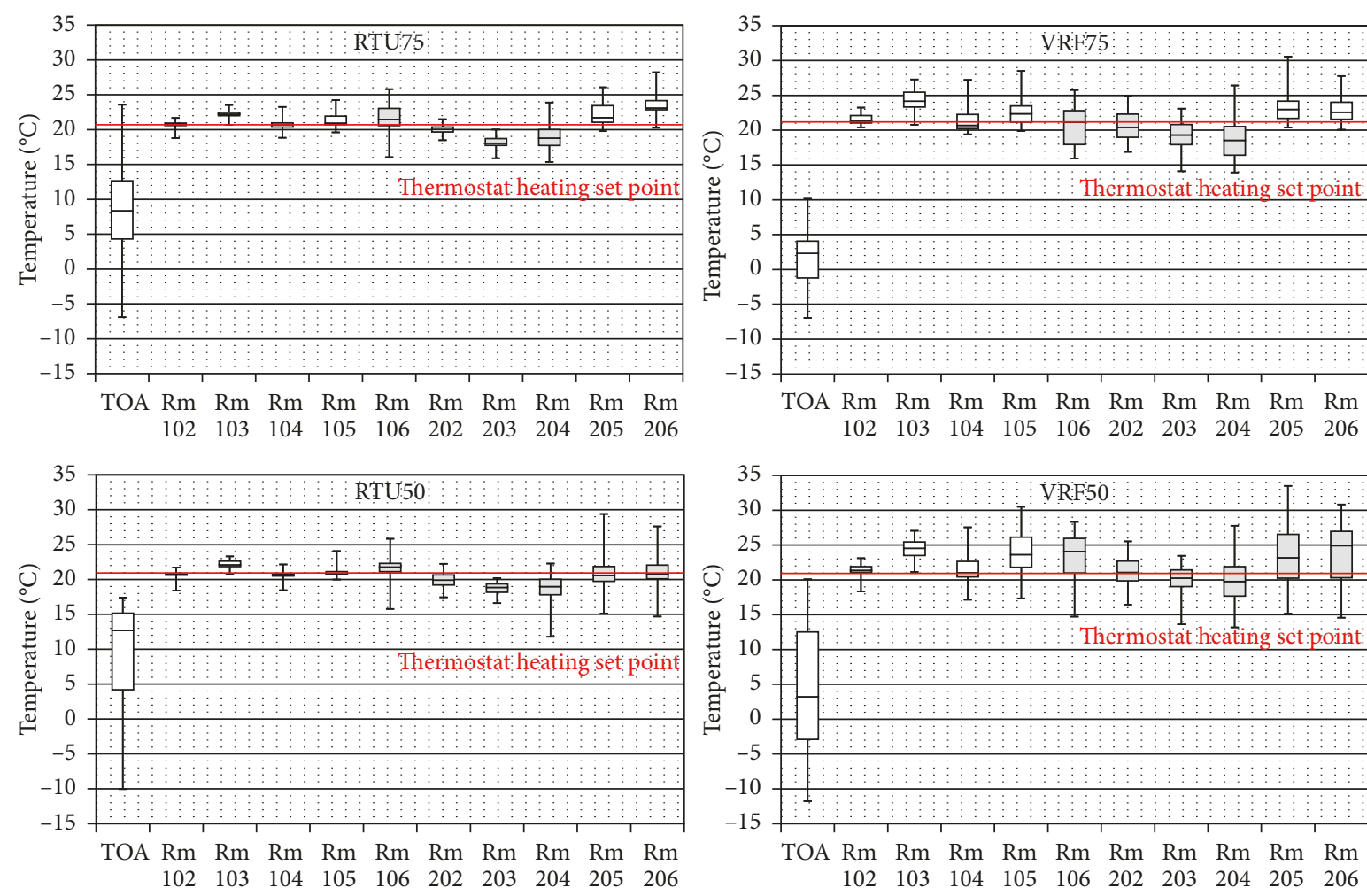

FIgURE 13: Room temperature during RTU and VRF system operation at different capacities.

defined in the outdoor air reset schedule. The VAV boxes and reheating equipment then operate independently to achieve the desired room conditions. In addition, the fresh air unit for the RTU did not operate below $5^{\circ} \mathrm{C}$, which may have led to underestimating the heating energy use.

Therefore, the additional heating energy required for conditioning the fresh air should also be calculated and included in the RTU model during the heating season. In light of these issues, a new methodology of developing an RTU model was considered.

4.2.1. RTU Power Consumption Analysis. For the RTU power consumption analysis, first, a delivered building load was calculated according to RTU operation, and an additional ventilation load needs to be calculated and added when the OAT is below $5^{\circ} \mathrm{C}$, as the DOAS fan did not operate below $5^{\circ} \mathrm{C}$. We assumed the additional ventilation load was met by additional VAV reheating. The regression model developed for additional VAV reheating due to an additional DOAS load is shown in Table 2 . The positive and negative building loads represent net heating and net cooling loads, respectively.

As a next step, hourly regression models for RTU hourly energy use (RTUDX + Fan), RTU cooling loads (RTU cooling $_{\text {), }}$ and hourly natural gas use $\left(\mathrm{NG}_{\text {heating }}\right)$ were developed separately. As a final step, the hourly VAV reheating energy, which could not be modeled easily, can be calculated as in (2). In this way, the VAV reheat is responding to the unmet building load similarly to the way it operates in the real world.

Figure 15 shows the calculated VAV reheating energy based on (2), and Figure 16 shows the hourly total RTU energy use, which is the sum of RTU energy, VAV reheating energy, and natural gas use. The final $\mathrm{R}^{2}$ values from the model, compared with the measured energy uses for RTU $100 \%, 75 \%$, and $50 \%$ operation, were $0.88,0.83$, and 0.79 , respectively. 

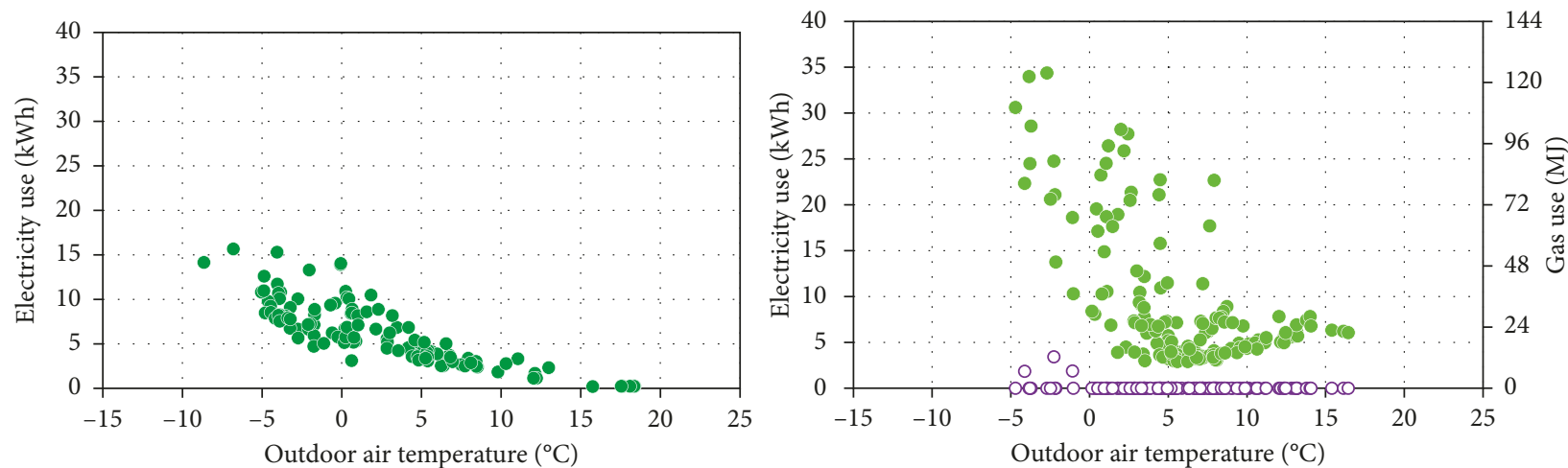

- Electricity use_VRF100

- Electricity use_RTU100

○ Gas use_RTU100
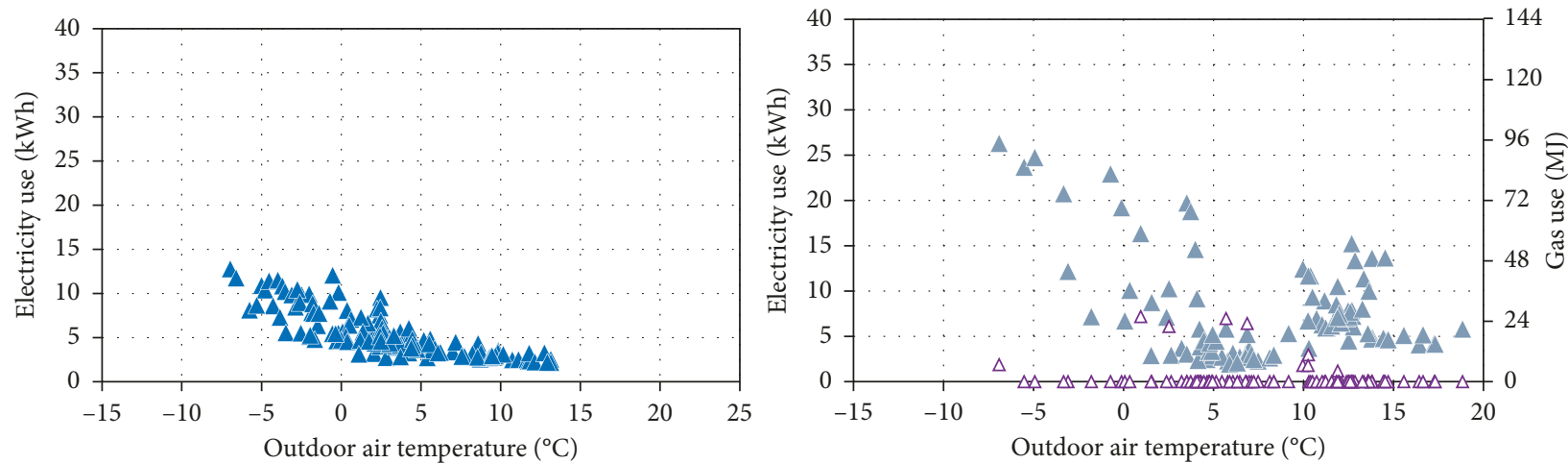

A Electricity use_VRF75

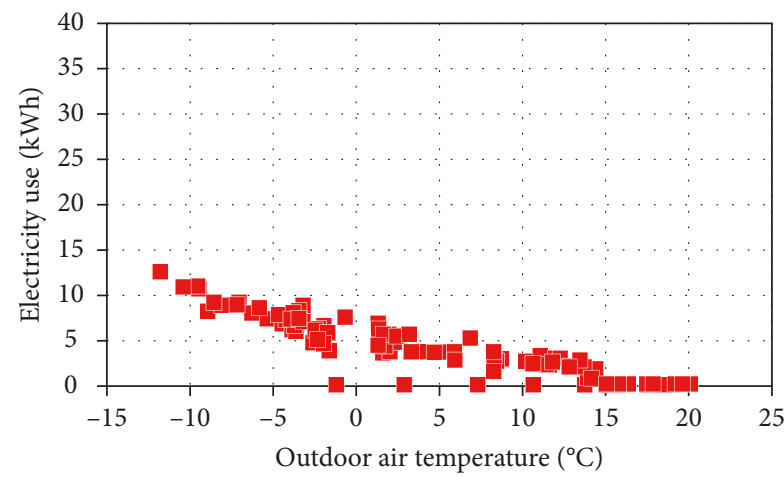

- Electricity use_VRF50

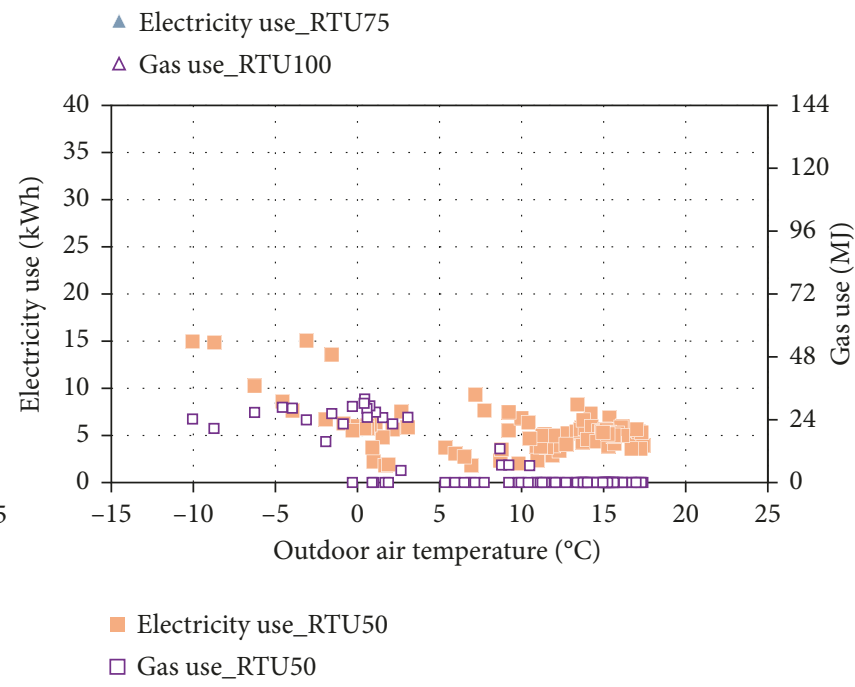

FIgURE 14: Comparison of hourly power consumption during occupied hours at varying loads.

Building load $(\mathrm{kWh})=\mathrm{RTU}_{\mathrm{mc}}\left(T_{\text {in }}-T_{\text {out }}\right)+\mathrm{VAV}_{\text {reheating }}$

$$
+ \text { M_DOAS }{ }_{\text {add }}
$$

where $\mathrm{RTU}_{\mathrm{mc}}\left(T_{\mathrm{in}}-T_{\text {out }}\right)(\mathrm{kWh})$ is the RTU delivered load (measured), $\mathrm{VAV}_{\text {reheating }}(\mathrm{kWh})$ is the VAV reheating energy (measured), and M_DOAS ${ }_{\text {add }}(\mathrm{kWh})$ is the ventilation load that should be added below $5^{\circ} \mathrm{C}$ of OAT (modeled)

$$
\begin{aligned}
& \mathrm{VAV}_{\text {reheating }}=\mathrm{M} \_ \text {Building load }+\mathrm{M}_{-} \mathrm{RTU}_{\text {cooling }} \\
& \text { - M_NG } \mathrm{N}_{\text {heating }} \text {, }
\end{aligned}
$$

where M_Building load ( $\mathrm{kWh}$ ) is the regression model for building load, $\mathrm{M}_{-} \mathrm{RTU}_{\text {cooling }}(\mathrm{kWh})$ is the regression model for RTU compressor work $(\mathrm{kWh}) \times \mathrm{COP}$, and $\mathrm{M}_{-} \mathrm{NG}_{\text {heating }}$ $(\mathrm{kWh})$ is the regression model for natural gas use $\times$ AFUE (80\%). 
TABLE 2: Regression models for RTU power consumption for heating season.

\begin{tabular}{|c|c|c|c|}
\hline Category & Operation & Regression models & $R^{2}$ \\
\hline \multirow{3}{*}{ Building load (kWh) } & RTU100 & $-0.8459 a-0.0002 b+0.2256 c^{2}-7.5075 c+68.98$ & 0.92 \\
\hline & RTU75 & $\begin{array}{c}0.01338 a^{2}-1.0334 a-0.0002 b+ \\
0.0488 c^{2}-2.1728 c+31.317\end{array}$ & 0.90 \\
\hline & RTU50 & $\begin{array}{c}0.01458 c^{2}-0.6714 a-0.000066 b+ \\
0.0434 c^{2}-1.4859 c+17.5349\end{array}$ & 0.89 \\
\hline \multirow{3}{*}{ M_DOAS add $(\mathrm{kWh})$} & RTU100 & $-0.1891 a+5.1779$ & N/A \\
\hline & RTU75 & $-0.1891 a+5.1779$ & N/A \\
\hline & RTU50 & $-0.1891 a+5.1779$ & N/A \\
\hline \multirow{4}{*}{ M_RTU DX + Fan $(\mathrm{kWh})$} & RTU100 & $0.0135 a^{2}+0.0261 a+1.91$ & 0.89 \\
\hline & RTU75 & $0.00881 a^{2}+0.00381 a+1.22$ & 0.86 \\
\hline & RTU50 (if $a<5^{\circ} \mathrm{C}$ ) & $0.00078 a^{2}+0.0125 a+1.68$ & 0.34 \\
\hline & RTU50 (if $a>5^{\circ} \mathrm{C}$ ) & $0.1304 a+0.315$ & 0.82 \\
\hline \multirow{3}{*}{ M_RTU $_{\text {cooling }}(\mathrm{kWh})$} & RTU100 & $-0.1119 a-0.3402 d^{2}+6.8119 d-13.0405$ & 0.98 \\
\hline & RTU75 & $2.6080 d-2.8632$ & 0.92 \\
\hline & RTU50 & $-0.09736 a-0.92115 d^{2}+7.4314 d-6.0403$ & 0.91 \\
\hline \multirow{3}{*}{ M_NG heating $(\mathrm{kWh})$} & RTU50 (if $a<4.4^{\circ} \mathrm{C}$ ) & $0.0586 a+7.3972$ & 0.07 \\
\hline & RTU50 (if $4.4^{\circ} \mathrm{C}<a<10^{\circ} \mathrm{C}$ ) & $-0.7315 a+9.0857$ & 0.91 \\
\hline & RTU50 (if $a>10^{\circ} \mathrm{C}$ ) & Zero & N/A \\
\hline
\end{tabular}

$a$ : outdoor air temperature $\left({ }^{\circ} \mathrm{C}\right)$; $b$ : global horizontal solar radiation $\left(\mathrm{W} / \mathrm{m}^{2}\right)$; $c$ : time of day; $d: \mathrm{M}_{-} \mathrm{RT} \mathrm{U}_{\mathrm{DX}+\mathrm{Fan}}$.

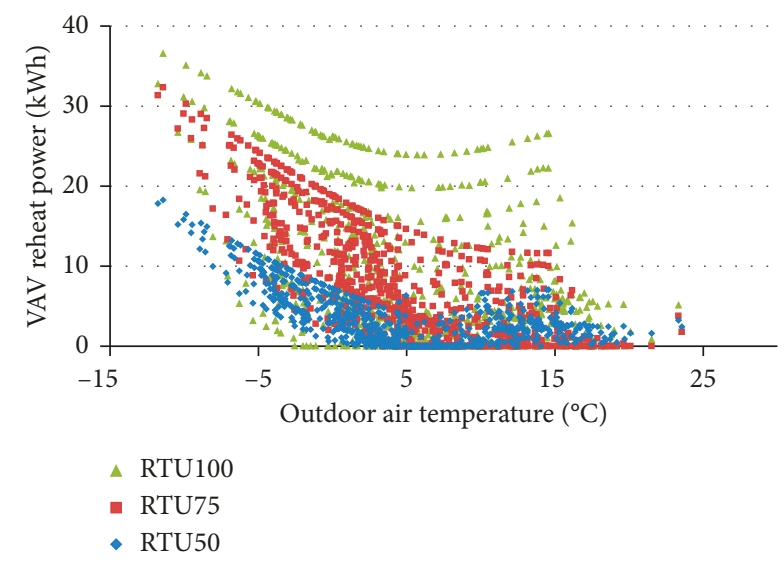

FIGURE 15: Calculated hourly RTU VAV reheating energy.

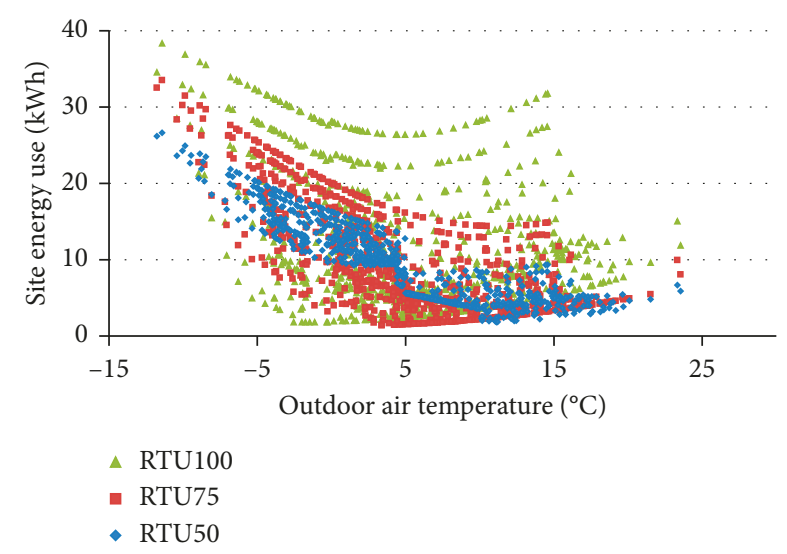

FIGURE 16: Hourly total RTU source energy (RTU + VAV + NG).

4.2.2. VRF Power Consumption Analysis. Regression models for hourly VRF energy use were also developed using multivariable regression, including a combination of OAT,
$\mathrm{OAT}^{2}$, hour of day, and hour of day ${ }^{2}$. Hourly solar radiation was also considered as a variable, but the regression model with this additional variable did not show significant improvement in the model fit. The developed models were as shown in Table 3.

Figure 17 shows the VRF energy use predicted for the entire heating season for 50\%, 75\%, and $100 \%$ VRF operation. Note that we assumed the minimal energy use of VRF system during heating season to be about $2.2 \mathrm{kWh}$, which is mainly used for the DOAS. In addition, it is assumed that this minimal VRF energy use would be seen for all heating operation above outdoor temperatures of $13^{\circ} \mathrm{C}$.

4.2.3. Predicted Heating Season Energy Use. Using the regression models for the RTU and VRF, weather-normalized energy use for the heating period was predicted. Unlike in the cooling season energy comparison, source energy savings were calculated, as the RTU energy use includes both electricity and natural gas use. For the conversion of site energy to source energy, factors of 3.365 and 1.092 were used for electricity and natural gas, respectively.

The final calculation shows that the VRF system saved $51 \%, 47 \%$, and $27 \%$ of the source heating energy use at $100 \%$, $75 \%$, and $50 \%$ loads, respectively (Figure 18). Unlike in cooling season operation, it appears that the RTU energy use dramatically dropped as the building was used partially (i.e., 75\% and 50\%). However, the energy use for the VRF in part-load operation did not show much difference, relatively, resulting in lower energy savings in part-load operation. For the RTU, since zone-level reheating represented the main use of energy for heating, partial room operation showed proportionally reduced reheating energy use as well as reduced RTU fan energy. For the VRF, the slight difference in energy use for full- and part-load operation was mainly due to the high heating energy use of the DOAS. As mentioned earlier, the DOAS supply temperature is higher than the discharge set 
TABLE 3: Regression models for VRF power consumption for heating season.

\begin{tabular}{lccc}
\hline Category & Operation & Regression models & $R^{2}$ \\
\hline & VRF100 & $1.4 a^{2}-371.2 a+74 c^{2}-2303 c+24391.7$ & 0.83 \\
VRF hourly energy use (Wh) & VRF75 & $19.7 a^{2}-561.6 a+22 c^{2}-659 c+11092.5$ & 0.73 \\
& VRF50 & $10.8 a^{2}-345.3 a+28 c^{2}-907 c+12286.8$ & 0.92 \\
\hline
\end{tabular}

a: outdoor air temperature $\left({ }^{\circ} \mathrm{C}\right) ; c$ : time of day.

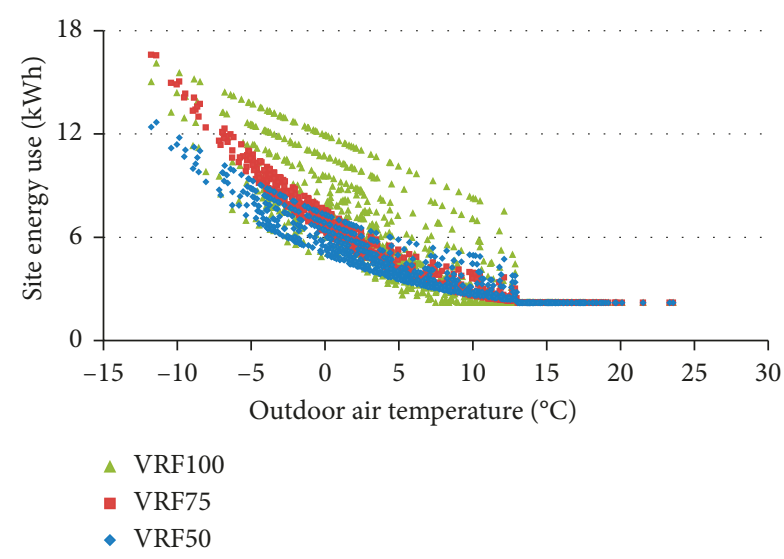

FIGURE 17: Hourly VRF energy predicted over the entire heating season.

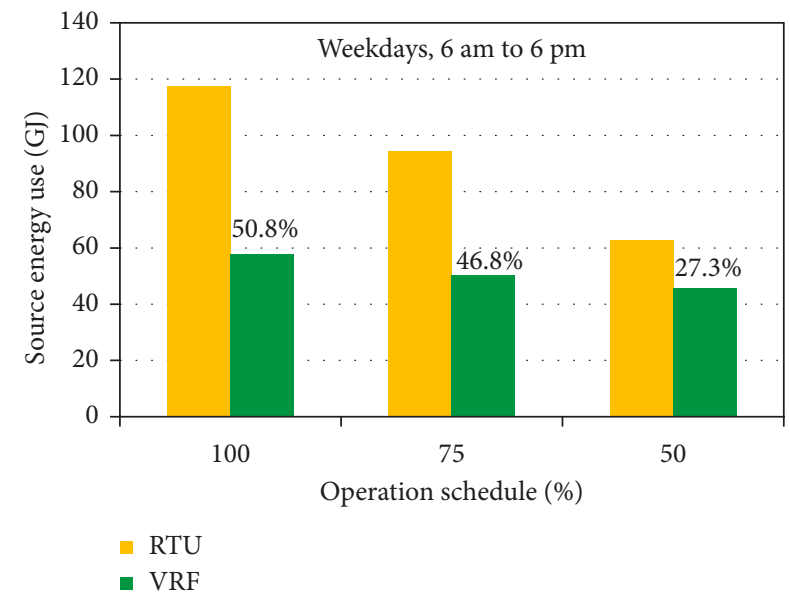

FIGURE 18: Comparison of VRF and RTU energy use over the entire heating season.

point temperature, and the DOAS was running continuously in all ten zones even during partial room operation. As the DOAS uses a major portion of the total heating energy, the VRF system energy use for all three operation modes is similar. It is expected that partial room operation would show lower energy use if there were no DOAS running or if the DOAS could provide conditioned air only to conditioned rooms. Additional saving analysis was performed assuming the VAV reheating would be provided by hot water generated by NG boiler. Given the $80 \%$ efficient boiler and a generic part-load performance curve, the hourly HW reheating energy was calculated and replaced the modeled electric resistant heating. The savings calculation with this scenario shows that the VRF system saved $18 \%, 9 \%$, and $8 \%$ of the source heating energy use at $100 \%, 75 \%$, and $50 \%$ loads, respectively. Given the relatively small size of the building and easy installation for electric reheating, however, the HW reheating with boiler room would not be ideal for this building.

4.3. COP Analysis. The performance of both the RTU and VRF systems was analyzed using 1-minute resolution data. Since the RTU system's two sources of heating are electrical resistance heat in the VAV boxes with a COP of 1 , and natural gas heating with a $\mathrm{COP}$ of 0.8 , it was expected that the overall site COP of this system would fall somewhere in that range. As seen in Figures 19 and 20, this was true for the $75 \%$ and $100 \%$ operating schedules for temperatures below approximately $5^{\circ} \mathrm{C}$. Above $5^{\circ} \mathrm{C}$, the RTU compressor ran to provide cooling that was then offset by the resistance heating in the VAV boxes, reducing the COP of the system. Similarly, the 50\% operating schedule also switched between natural gas heating and cooling with reheating at temperatures below $5^{\circ} \mathrm{C}$ while trying to maintain the appropriate supply air temperature from the RTU. The COPs of the VRF system ranged from 1.2 to 2.0 , which are lower than expected but still substantially higher than the COP of the RTU system. It is also of interest to examine how the VRF system efficiency varied with the fraction of indoor rated capacity that was actively heating. In Figure 21, the marker color indicates the COP, along with the data labels, and the marker shape differentiates among the three operating schedules.

The more active units there are, the larger is the indoor heat exchanger area, which should increase the efficiency. There also appears to be a more significant drop in efficiency below the 0.4 fraction of indoor rated capacity, which may correlate to the minimum compressor operating speed. Below this point, the compressor may not be able to reduce its speed any further, and the use of a hot gas bypass may be required for the outdoor unit to match the required capacity of the indoor units. The reduced efficiency might also be due to heat that was delivered to inactive units and therefore was not measured in this paper. It was observed, through elevated supply and return air temperatures, that hot refrigerant was still passing through the indoor coils of units that were not actively heating and did not have their indoor fans running. This would provide some amount of heat to the room via natural convection and radiation. The amount of heat probably would not be large, but since most of the indoor units were not active most of the time, it could add up to significant unmeasured, albeit unrequested, heating 


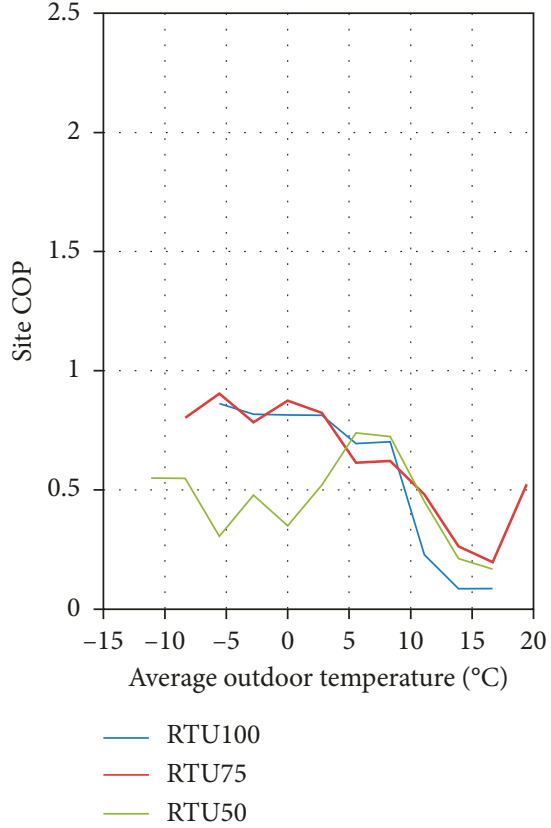

(a)

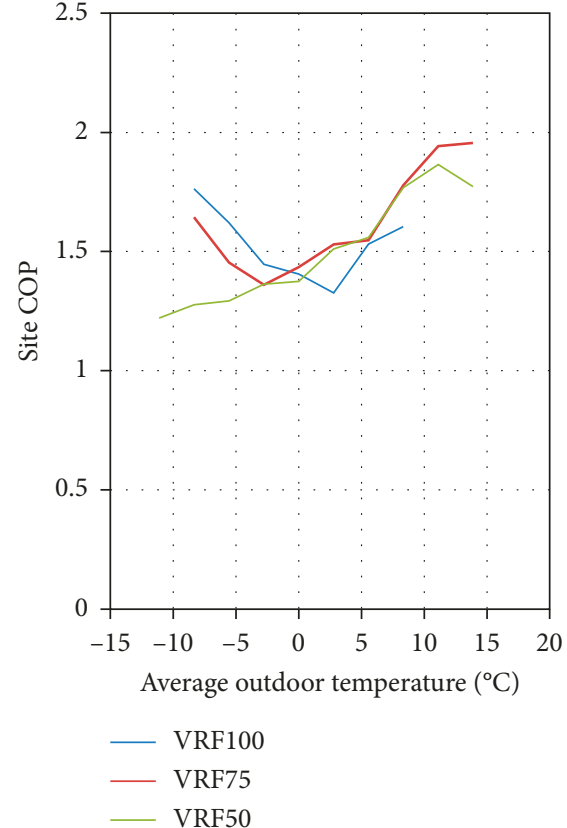

(b)

FIGURE 19: Site COPs of RTU and VRF systems relative to outdoor air temperature for all operating schedules.

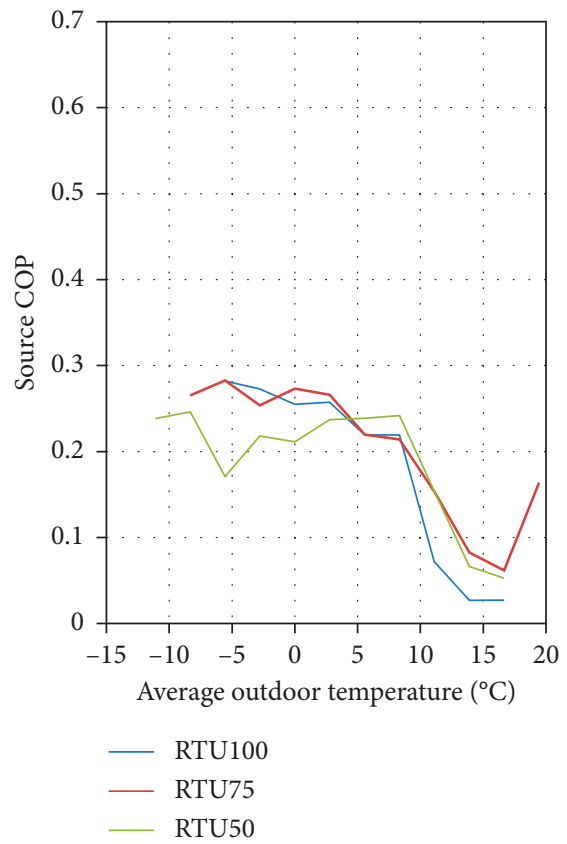

(a)

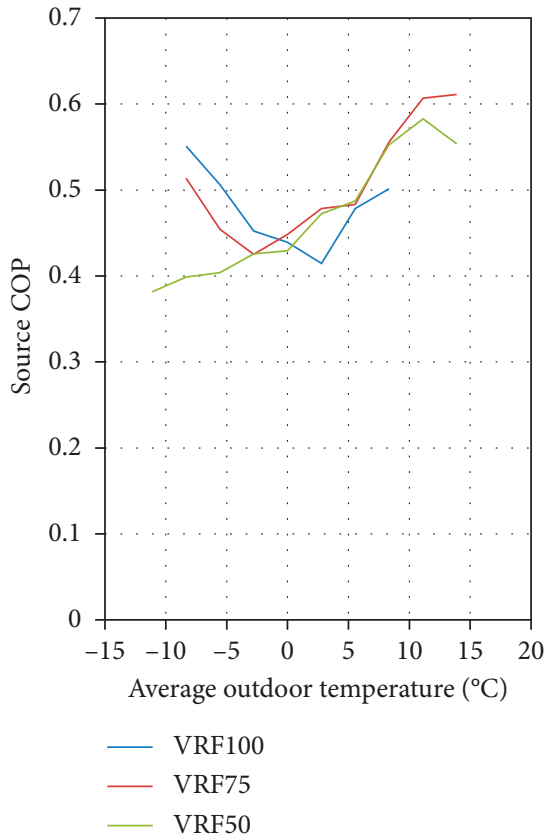

(b)

FIGURE 20: Source COPs of RTU and VRF systems relative to outdoor air temperature for all operating schedules.

capacity. These factors could explain the lower than expected COPs seen in the VRF system.

\section{Conclusion}

This paper compares the full and part-load performance of a VRF system with the baseline RTU/VAV system in a two- story, $300 \mathrm{~m}^{2}$ multizone building with emulated office occupancy. To accomplish this, during heating and cooling season, full and part-load conditions (i.e., $100 \%, 75 \%$, and $50 \%$ loads) in the building were maintained alternately by conditioning either the entire building or selected zones and emulating the occupancy accordingly. During the measuring period, each system was operated alternately under 


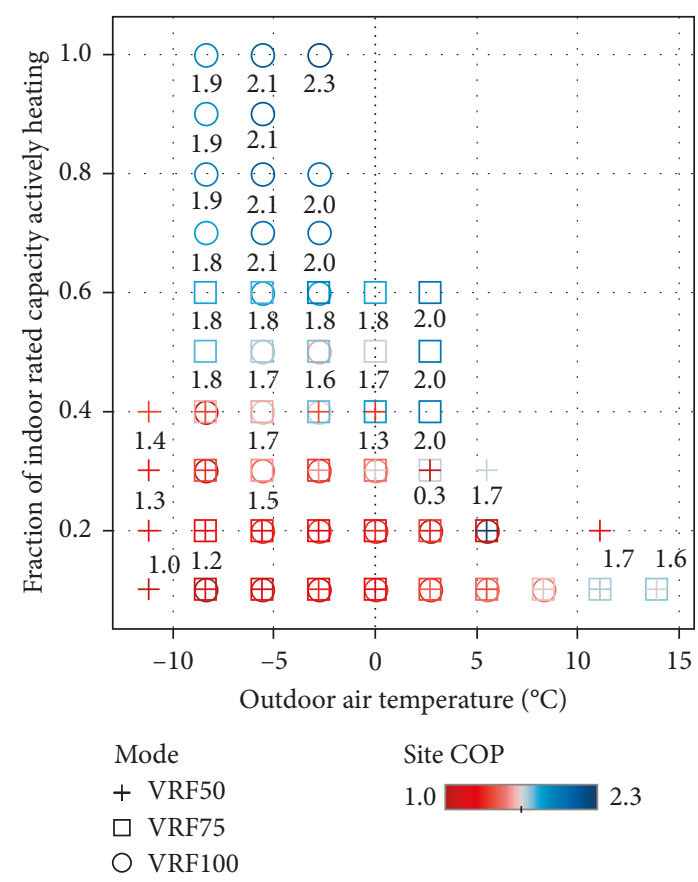

FIGURE 21: Impact of the rated capacity of active indoor units on the efficiency of the VRF system in winter.

each of the three load conditions for 2 to 3 days, and the system parameters, indoor and outdoor conditions, loads, and energy use were monitored. The system performance was evaluated in terms of weather-normalized HVAC energy consumption, the ability to maintain the desired indoor temperatures in the conditioned zones, and the seasonal average COP. However, the tests such as latent, randomly part loads and measuring period, DOAS to nonDOAS comparison were not carried out in this paper, and it is needed to be examined through further studies. The following are the key findings and lessons learned from this case study.

\subsection{Cooling Season Analysis}

(i) Hourly zone temperature analysis shows that both RTU and VRF systems maintained room temperature very well, especially in the first-floor rooms. The second-floor rooms were generally slightly high. The VRF system maintained room temperature in a slightly tighter range compared with the RTU system.

(ii) The energy savings for the VRF system compared with the RTU system for the cooling season are estimated to be $30 \%, 37 \%$, and $47 \%$ under the 100,75 , and $50 \%$ load conditions, respectively.

(iii) The COP analysis based on 1-hour data shows that the average cooling COP was 4.2, 3.9, and 3.7 for the VRF system and 3.1, 3.0, and 2.5 for the RTU system under the $100 \%, 75 \%$, and $50 \%$ load conditions.

(iv) The quasi-steady-state data analysis indicates that the VRF system operates most efficiently when all indoor units are actively cooling and the compressor is operating at a reduced speed.

\subsection{Heating Season Analysis}

(i) In general, the RTU system provided better thermal control for most rooms during heating season since the RTU system can provide simultaneous cooling and heating for different rooms. The analysis shows that the VRF system overheated some rooms. As the installed VRF system cannot provide simultaneous cooling and heating, the majority of the rooms were overheated when they might need cooling.

(ii) Multivariable regression models were developed for the RTU and VRF hourly energy use. The energy savings for the VRF system compared with the RTU system for the heating season are estimated to be $51 \%, 47 \%$, and $27 \%$ under the $100 \%, 75 \%$, and $50 \%$ load conditions, respectively.

(iii) During the heating season, the COPs of the VRF system ranged from 1.2 to 2.0 , which were lower than expected but still substantially higher than the COPS of the RTU system. The RTU system COPs were less than 1 , which was expected because the system's two sources of heating are electrical resistance heat in the VAV boxes, with a COP of 1 , and natural gas heating, with a COP of 0.8 .

\section{Disclosure}

This effort was supported by Samsung Electronics and U.S. Department of Energy. Neither the United States Government nor any agency thereof, nor any of their employees, makes any warranty, express or implied, or assumes any legal liability or responsibility for the accuracy, completeness, or usefulness of any information, apparatus, product, or process disclosed, or represents that its use would not infringe privately owned rights. Reference herein to any specific commercial product, process, or service by trade name, trademark, manufacturer, or otherwise, does not necessarily constitute or imply its endorsement, recommendation, or favoring by the United States Government or any agency thereof. The views and opinions of authors expressed herein do not necessarily state or reflect those of the United States Government or any agency thereof. This manuscript has been authored by UT-Battelle, LLC, under Contract Number DE-AC05-00OR22725 with the U.S. Department of Energy. The United States Government retains and the publisher, by accepting the article for publication, acknowledges that the United States Government retains a nonexclusive, paid-up, irrevocable, world-wide license to publish or reproduce the published form of this manuscript, or allow others to do so, for United States Government purposes. This article was written based on two technical reports. Further details for the study can be found in Piljae Im, Mini Malhotra, and Jeffrey D. Munk (2016), Evaluation of Variable Refrigerant Flow Systems Performance on Oak Ridge National Laboratory's Flexible Research Platform: Part 1: Cooling Season Analysis, ORNL/TM-2016/364, and Part 2: Heating Season Analysis, ORNL/TM-2016/365, Oak Ridge, TN. USA. 


\section{Conflicts of Interest}

The authors declare that they have no conflicts of interest.

\section{Acknowledgments}

This work was supported by the National Research Foundation of Korea (NRF) grant funded by the Korea government (MSIT) (no. 2017R1A2B2006424).

\section{References}

[1] B. Thornton and A. Wagner, Variable Refrigerant Flow Systems, Prepared for the General Services Administration, Pacific Northwest National Laboratory, Richland, WA, USA, 2012.

[2] W. Goetzler, "Variable refrigerant flow systems," ASHRAE Journal, vol. 49, pp. 24-31, 2007.

[3] A. Amarnath and M. Blatt, "Variable refrigerant flow: an emerging air conditioner and heat pump technology," in Proceedings of 2008 ACEEE Summer Study on Energy Efficiency in Buildings, vol. 3, pp. 1-13, Washington, DC, USA, August 2008.

[4] T. Aynur, Y. Hwang, and R. Radermacher, "Simulation comparison of VAV and VRF air conditioning systems in an existing building for the cooling season," Energy and Buildings, vol. 41, no. 11, pp. 1143-1150, 2009.

[5] Building Services Research and Information Association, World Air Conditioning Market Grows Thanks to Hot Spots, https://www.bsria.co.uk/news/article/world-air-conditioningmarket-grows-thanks-to-hot-spots/.

[6] P. Im, J. Munk, and A. Gehl, "Evaluation of variable refrigerant flow system performance and the enhanced control algorithm on oak ridge national laboratory's flexible research platform: part 1 cooling season analysis," ORNL Report ORNL/TM-2016/364, Oak Ridge National Laboratory, Oak Ridge, TN, USA, 2016.

[7] P. Im, J. Munk, and A. Gehl, "Evaluation of variable refrigerant flow system performance and the enhanced control algorithm on oak ridge national laboratory's flexible research platform: part 2 heating season analysis," ORNL Report ORNL/TM-2016/365, Oak Ridge National Laboratory, Oak Ridge, TN, USA, 2016.

[8] P. Im, H. Cho, K. Dongsu, and S. Cox, "Evaluation of variable refrigerant flow system performance and the enhanced control algorithm on oak ridge national laboratory's flexible research platform: part 3 simulation analysis," ORNL Report ORNL/TM-2016/386, Oak Ridge National Laboratory, Oak Ridge, TN, USA, 2016.

[9] L. E. Southard, X. Liu, and J. D. Spitler, "Performance of HVAC systems at ASHRAE HQ," ASHRAE Journal, vol. 56, no. 9, p. 14, 2014.

[10] ASHRAE, ANSI/ASHRAE Standard 55-2013, Thermal Environmental Conditions for Human Occupancy, American Society of Heating, Refrigeration and Air-Conditioning Engineers, Washington, DC, USA, 2013. 


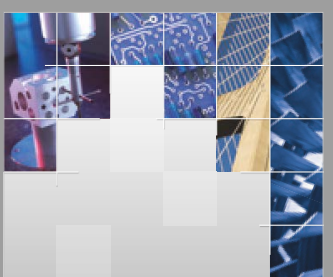

\section{Enfincering}
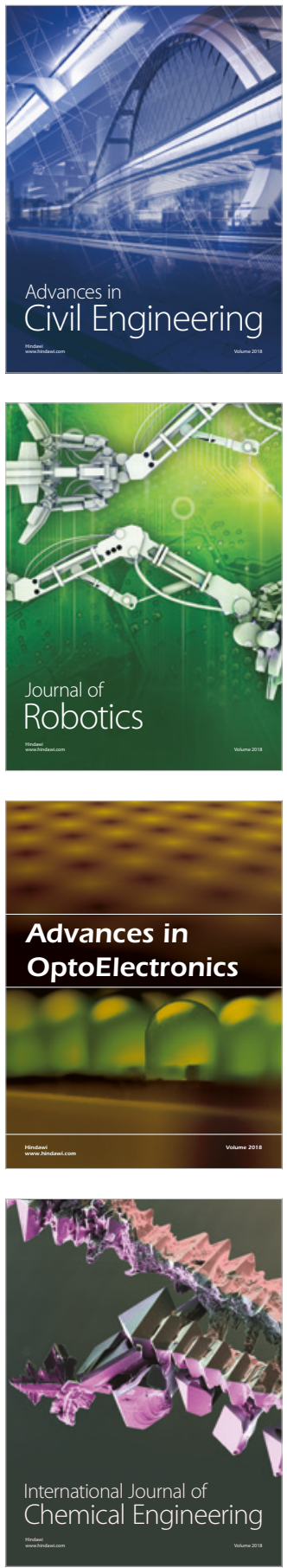

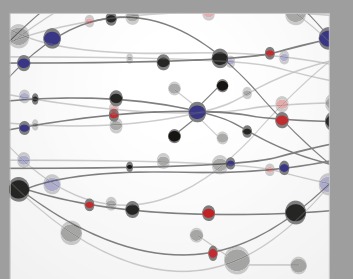

\section{Rotating \\ Machinery}

The Scientific World Journal

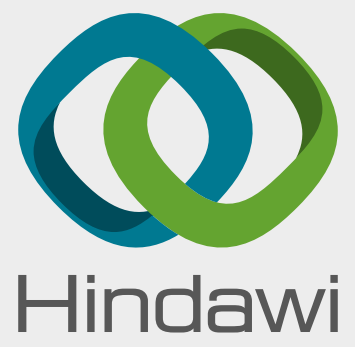

Submit your manuscripts at

www.hindawi.com
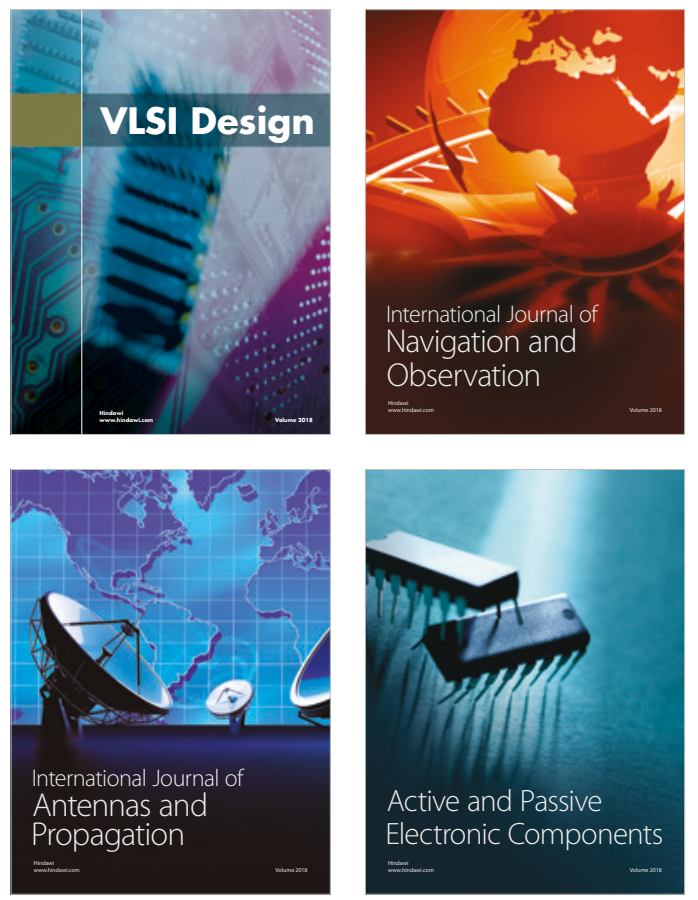
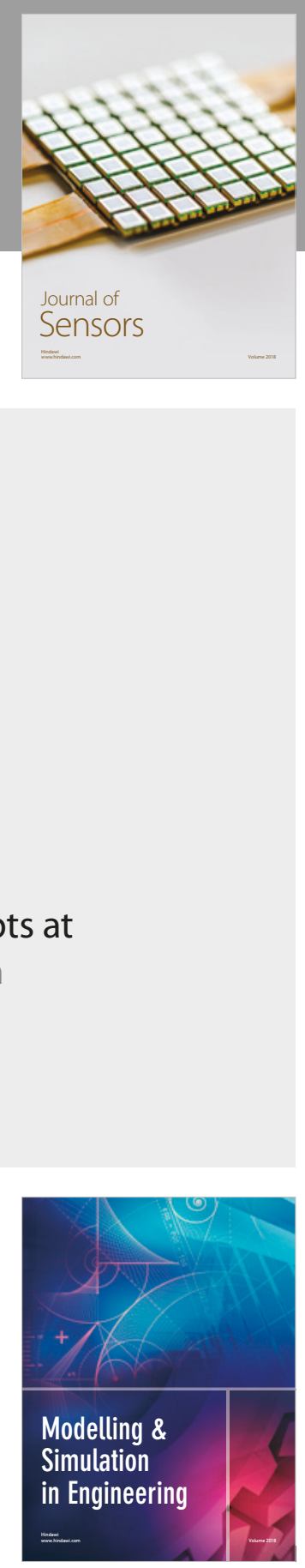

\section{Advances \\ Multimedia}
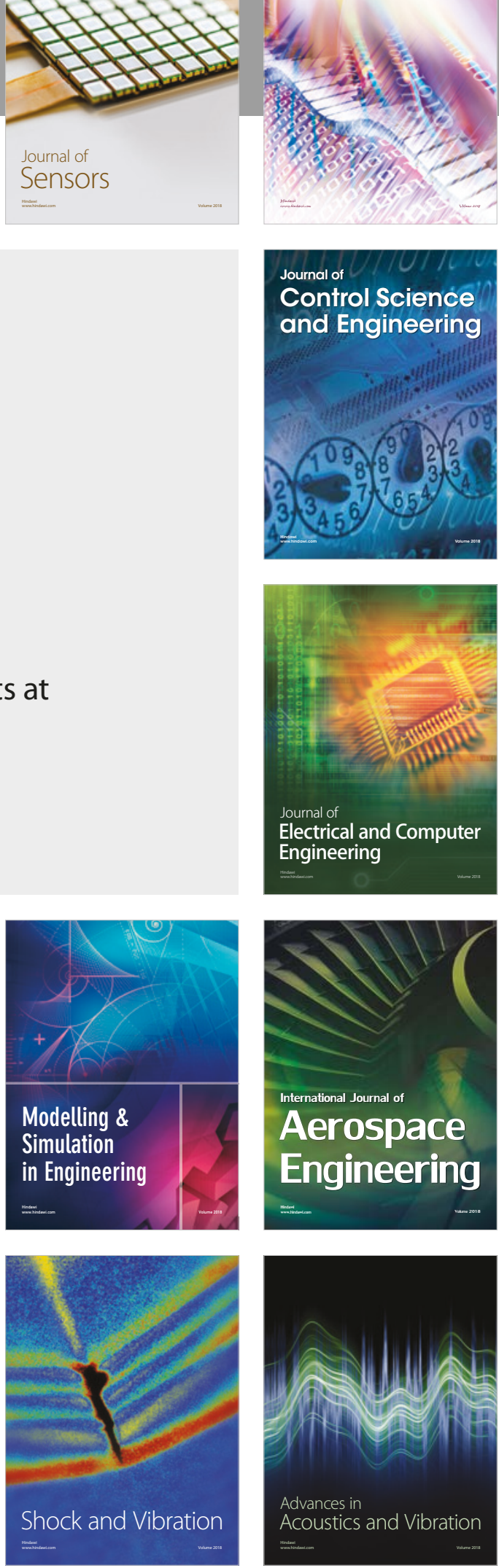